\title{
La financiación de los partidos políticos The funding of political parties
}

\author{
Emilio Pajares Montolío \\ Universidad Carlos III de Madrid \\ epajares@der-pu.uc3m.es
}

Recibido / received: 04/03/2016

Aceptado / accepted: 10/06/2016

DOI: http://dx.doi.org/10.20318/eunomia.2016.3287

\begin{abstract}
Resumen
Aunque sujeta a cambios relativamente frecuentes, alguno muy reciente, la legislación sobre financiación de partidos políticos sigue en España un modelo claramente asentado en las contribuciones públicas, que reciben los partidos en función de varios conceptos y por parte de diversas instituciones, hasta el punto de convertirse en su principal fuente de recursos, sin que, más allá del ámbito electoral, sus gastos sean objeto de límites o incluso de prohibiciones.

Sin que quepa imputar este hecho a unas previsiones legales que han tendido a hacerse cada vez más restrictivas, la financiación que reciben por otras vías es mucho menor, tanto en forma de donaciones (legales) como por las cuotas o aportaciones de sus miembros, en un desequilibrio que tiene importantes consecuencias para definir su posición en el sistema político. Se cierra ese modelo con un sistema de control que reposa básicamente en la atribución al Tribunal de Cuentas de la fiscalización de la contabilidad anual y electoral de los partidos, sin que hasta las últimas reformas se haya prestado especial atención a la necesaria transparencia e incluso a la correcta articulación de las sanciones por la infracción de las normas en la materia.
\end{abstract}

\section{Palabras clave}

Partidos políticos; subvenciones a partidos políticos; gastos electorales; donaciones a partidos; control de la financiación de partidos y Tribunal de Cuentas; corrupción.

\begin{abstract}
Although subjected to relatively frequent changes, some very recent, legislation on political parties funding, follow in Spain a model clearly based on public contributions, based on several concepts and from various institutions, to the extent of becoming their main source of income, without their expenses being subjected to limits or prohibitions, beyond the electoral arena. Not being possible to attribute this fact to current legal provisions, which have tended to be increasingly more restrictive, the funding received from other sources is much lower, both in the form of (legal) grants, or from member fees and contributions, creating an imbalance that has important consequences on the definition of their position in the political arena. This model is completed with a control system based on the conferral to the Court of Auditors of powers to audit the annual and electoral parties accounting books, but it has been only until the recent reforms that special attention has been paid to the necessary transparency or even to the correct regulation of sanctions for violation of the rules on the matter.
\end{abstract}




\title{
Keywords
}

Political parties; direct and indirect public funding; election expenses; donations; public monitoring of political finance and Court of Auditors; corruption.

\begin{abstract}
SUMARIO. 1. Introducción. 2. Una generosa financiación pública, procedente de varias fuentes. 2.1. Subvenciones para el funcionamiento de los partidos. 2.2. Subvenciones a los grupos. 2.3. Subvenciones por gastos electorales y otras contribuciones (indirectas) en periodo electoral. 2.4. Subvenciones por gastos de campañas de referéndum. 2.5. Subvenciones a fundaciones vinculadas a partidos políticos. 3. Algunos gastos (electorales) prohibidos y limitados. 4. Una financiación privada muy modesta. 4.1. Donaciones. 4.2. Operaciones de crédito. 4.3. Cuotas y aportaciones. 4.4. Otras fuentes. 4.5. El régimen tributario de los partidos y de sus ingresos. 5. ¿Un control efectivo? 5.1. Requisitos contables. 5.2. Procedimientos de fiscalización. 5.2.1. Sujetos obligados. 5.2.2. Informes del Tribunal de Cuentas. 5.3. Publicidad de la contabilidad. 5.4. Sanciones.
\end{abstract}

\section{Introducción}

Susceptible de ser analizada desde muy diversas perspectivas, la regulación de la actividad económica de los partidos políticos y de quienes concurran en candidaturas electorales ha resultado tan trascendente como, en la mayoría de los casos, insatisfactoria respecto a los objetivos que se pretende conseguir con ella. Su relevancia viene ligada a la conformación del sistema de gobierno como democracia de partidos (o electoral), por lo que normar cuestiones relacionadas con la financiación de su actividad, esto es, con el uso y origen de los muy cuantiosos medios económicos que necesitan para realizarla, parece lógico si se quiere garantizar su estabilidad y continuidad, en tanto los partidos son piezas esenciales de la democracia (pero con el efecto paralelo de acentuar la centralización y burocratización de las estructuras partidistas y reducir la afiliación, si ya no dependen de las contribuciones de los militantes). Algo parecido se puede decir respecto a la igualdad de la competencia política que trata de asegurar (en algunos casos más bien ha cerrado el paso a la aparición de nuevas opciones, beneficiando especialmente a las opciones con mejor situación de partida) o sobre el sometimiento a control público de sus fuentes de financiación y de sus gastos (mediante instrumentos que difícilmente pueden asegurar sobre todo cuál es el origen de los fondos que manejan). Tampoco se ha evitado totalmente que dependan de poderes económicos o sociales, de grupos de presión e incluso de redes ilegales de financiación, ni que el dinero se convierta en un factor determinante en la vida política (Del Castillo, 1985) ${ }^{1}$.

En una muy sumaria relación inicial, hay que considerar al menos cuatro ámbitos sobre los que, con muy diverso alcance, puede proyectarse la intervención estatal en esta materia, con una relación mayor o menor con los objetivos citados anteriormente, que serán los que se analicen a continuación respecto a la legislación española actualmente vigente. El más notable, sin duda, es el de la

\footnotetext{
${ }^{1}$ En todo caso, conviene recordar, como hacen Rodríguez Teruel, Baras, Barberà y Barrio (2013: 6465), que los problemas de la financiación de partidos no sólo tienen que ver con las normas que los regulan, sino que exigen también plantearse el modo en que se articula la representación política, las prácticas sociales y la existencia, si la hubiera, de una opinión pública crítica, que favorezca la rendición de cuentas, la transparencia en este ámbito.
} 
financiación pública, puesto que buena parte de esas regulaciones ha estado destinada a contribuir económicamente, a subvencionar a los partidos, de acuerdo a varias modalidades que pueden afectar a la entidad que financia (Administraciones o parlamento), a la actividad subvencionada (todas, sólo las electorales, sólo las parlamentarias), al sujeto que recibe esa financiación (partido, candidato, grupo parlamentario, fundación, prensa u otras organizaciones ligadas con ellos) o a los criterios para determinar quién accede a esa financiación pública y cómo se distribuyen las subvenciones y/o prestaciones materiales que se facilitan por los poderes públicos.

Con una orientación más bien limitadora o incluso prohibitiva se ha abordado la financiación privada, sujeta en ocasiones a ciertos requisitos de publicidad y, eventualmente, a incentivos de carácter fiscal que tienden a estimularla. Una orientación en parte semejante (límites y prohibiciones) puede tener el tratamiento de los gastos (sobre todo los electorales). Con relación más o menos directa con el resto de medidas, estas previsiones habitualmente se cierran con el establecimiento de sistemas de control de la actividad económica, con intervención de un organismo público (el propio parlamento, los que actúen en periodo electoral, los de control contable o uno específicamente creado para esta función) y sanciones, sean económicas, penales o electorales (privación del cargo).

Estas medidas se han combinado de muy diferente manera, dando lugar a regulaciones diversas, a veces sólo parciales, en las que se aprecia no tanto una voluntad de introducir un determinado sistema elaborado y coherente, ajustado a la posición de los partidos en el sistema político, como la de dar respuesta a acontecimientos muy concretos, ligados a escándalos de naturaleza política o a las necesidades más o menos coyunturales de los partidos, lo que hace que los cambios sean frecuentes, en un Derecho que se manifiesta como un supuesto de autorregulación: son los propios partidos (o el que tenga mayoría) los que aprueban las normas que les benefician, limitan o controlan, con las dificultades que conlleva para su observancia (Iglesias, 2016: 124-125).

En buena medida, la legislación española participa de estas características: en primer lugar, el reconocimiento constitucional de la relevante posición de los partidos políticos (artículo $6 \mathrm{CE}$ ) brinda cobertura más que suficiente para concebir, con carácter general, no limitado a su financiación, el Derecho de partidos como un conjunto de privilegios y obligaciones (STC 3/1981), previstos expresamente en el texto constitucional (como la democracia interna) o derivados directamente de las funciones que se les asigna, como sería el caso de su financiación, para cuya regulación, al no imponer ningún modelo, cuenta el legislador con un amplio margen que en todo caso no puede ignorar esa relevancia constitucional (Sánchez Muñoz, 2013: 163$)^{2}$.

\footnotetext{
${ }^{2}$ No es muy frecuente que en las normas constitucionales, a pesar de la relevancia de la materia para un Estado democrático, haya pronunciamientos sobre la financiación de los partidos, aunque sí hay algún ejemplo significativo, como la Ley fundamental para la República Federal de Alemania, que, tras afirmar que los partidos políticos participan en la formación de la voluntad política del pueblo, establece que "deben dar cuenta públicamente de la procedencia y uso de sus recursos, así como de su patrimonio". Más peculiar resulta, en el ordenamiento español, que apenas haya sido objeto de consideración en la jurisprudencia constitucional la financiación partidista, cuando en otros países ha contribuido de forma determinante en la conformación de estas normas, con diversas orientaciones y puntos de partida: mientras en España sólo ha sido objeto de referencias muy genéricas, porque el Tribunal Constitucional no ha tenido que resolver ningún recurso o cuestión que tuviera por objeto directo los problemas de la financiación (así, por ejemplo, en la STC 3/1981, de 2 de febrero, al abordar otras cuestiones sobre el régimen jurídico de los partidos políticos, se menciona que reciben ayuda financiera del Estado no por el mero hecho de existir, sino por cumplir de manera efectiva con las
} 
El tratamiento legal de la cuestión presenta otra particularidad, pues debe atenderse tanto a lo previsto en la Ley orgánica 8/2007, de 4 de julio, de financiación de los partidos políticos (LOFPP), como en la Ley orgánica 5/1985, de 19 de junio, del régimen electoral general (LOREG). Esa diferenciación se inició con la aprobación, durante la transición política, de normas electorales (el Real decreto-ley 20/1977, de 18 de marzo, que contenía algunas disposiciones sobre financiación pública y privada, básicamente) y posteriormente sobre partidos (la Ley 4/1978, de 4 de diciembre, que apenas preveía que se otorgaran subvenciones anuales con cargo a los presupuestos generales del Estado). Sin que se alegara una razón de fondo sólida, este carácter fragmentado se mantuvo cuando en la década siguiente se aprueban la ya citada LOREG y la primera norma que aborda específicamente esta cuestión, la Ley orgánica 3/1987, que establecerán ya un sistema que, en sus líneas maestras, sique vigente a pesar de las, hasta cierto punto, numerosas reformas posteriores que se han registrado en uno y otro ámbito, incluyendo la aprobación de una nueva ley de financiación de partidos en 2007 , modificada a su vez en 2012 y más recientemente en 2015: sin duda, cabe calificarla, con Lucas Murillo de la Cueva (1993), de "legislación interminable", pues en ella se cumple, como se verá a continuación, esa condición de normas elaboradas con carácter reactivo o casuístico (Iglesias, 2016: 129).

\section{Una generosa financiación pública, procedente de varias fuentes}

Se puede afirmar que el primer objeto de estas normas, su fin principal, es la regulación de la financiación pública, a través de subvenciones: previstas ya en las primeras normas sobre partidos y elecciones, ante la falta de recursos propios de formaciones políticas que habían empezado a desarrollar su actividad en las especiales circunstancias de la transición a la democracia (reducido número de militantes y carencia de recursos propios, campañas costosas, organización permanente y de cierta extensión, para cumplir con las funciones de un sistema democrático cuyo funcionamiento depende básicamente de los partidos), apenas se han puesto en discusión salvo en tiempos recientes, en un contexto de crisis económica y de desafección hacia el sistema político que ha llevado a cuestionar de forma generalizada la organización constitucional del Estado. En todo caso, más allá de circunstancias coyunturales, la conexión entre estas prestaciones estatales y la garantía de que los partidos pueden cumplir sus funciones constitucionales en condiciones mínimas de igualdad es evidente ${ }^{3}$.

funciones que constitucionalmente se les atribuyen), estos asuntos han llegado en numerosas ocasiones al Tribunal Constitucional Federal, lo que quizá se pudiera explicar por contar con la expresa regulación constitucional que se acaba de mencionar, pero también hay decisiones del Consejo Constitucional muy relevantes cuando el ordenamiento francés tiene un planteamiento más similar al español (se reconoce constitucionalmente la función de los partidos, pero sin mención a su financiación) e incluso en EEUU han sido capitales las sentencias del Tribunal Supremo a pesar de que ninguna norma constitucional se refiere a partidos o candidaturas.

${ }^{3}$ En la jurisprudencia constitucional de otros países se pueden encontrar algunas interesantes reflexiones sobre la fundamentación de las subvenciones: concretamente, en Alemania la Sentencia de 24 de junio de 1958 (BVerfGE 8, 51) declaró que no había un deber de financiación estatal, aunque cabía realizarla bajo el principio de igualdad. Las subvenciones anuales que inmediatamente después se empiezan a distribuir fueron consideradas en la Sentencia de 19 de julio de 1966 (BVerfGE 20, 56) incompatibles con la función de los partidos políticos: si al Estado no le corresponde la formación de la voluntad popular, tampoco la de financiar a los partidos en cuanto organizaciones sociales, que han de mantener su independencia respecto al Estado, salvo en el ámbito electoral, ya que la contribución que realizan a la formación de la voluntad estatal, que además es perfectamente cuantificable, puede ser objeto de restitución por el Estado. Causa inmediata de la aprobación de una Ley de partidos políticos el año siguiente, que contiene una detallada disciplina sobre su funcionamiento interno (con garantías de participación de la militancia) y sobre su financiación, incluyendo el desarrollo de la obligación constitucional de rendición de cuentas, el Tribunal reconsideró su posición en la Sentencia de 9 de abril 


\subsection{Subvenciones para el funcionamiento de los partidos}

La LOFPP contiene en primer lugar una regulación detallada de las subvenciones anuales a cargo de los presupuestos generales del Estado (lo que se ha dado en llamar la financiación ordinaria), destinadas, según su art. 3.1, a financiar tanto los gastos de funcionamiento de los partidos, sin mayor determinación o concreción, como, desde la aprobación de la Ley orgánica 1/2003, también los específicamente destinados a seguridad (hay que incluirlas en partidas por separado), a las que accederán las formaciones políticas que tengan representación en el Congreso de los Diputados ${ }^{4}$.

Lo que no establece la LOFPP es su cuantía, ni siquiera un máximo o un mínimo, ni se vincula con ninguna actividad de los partidos ni con la voluntad de los contribuyentes ${ }^{5}$ : simplemente, ha de fijarse una cantidad global en la ley de presupuestos generales del Estado de cada ejercicio. Con Sánchez Muñoz (2013: 168) cabe apuntar que para determinarlas habría que atender al doble criterio de que resultaran suficientes y estables, de modo que les permitieran atender sus "necesidades económicas", pero en este ámbito no ha resultado posible establecer cuáles son éstas, por lo que cada año se establece según el criterio que tengan las Cortes Generales.

Lo que sí está previsto en cambio es que se distribuyan en función del número de escaños y de votos obtenidos por cada partido político en las últimas elecciones al Congreso de los Diputados (art. 3.2): las dos partidas consignadas en los presupuestos se dividen en tres partes iguales, que se distribuyen una en proporción al número de escaños obtenidos por cada partido político en dichas elecciones y las dos restantes proporcionalmente a todos los votos obtenidos por cada partido en dichas elecciones. Dos primeras consideraciones cabe formular acerca de estas reglas:

a) Quedan excluidas de las subvenciones las formaciones extraparlamentarias, con independencia de los resultados que hayan obtenido (en algunas ocasiones han sido de centenares de miles de votos), con el efecto de

de 1992 (BVerfGE 85, 264), para admitir, desde una posición de partida similar, una financiación anual (pues no cabe distinguir radicalmente entre las actividades electorales y las demás), siempre que sea parcial y, por tanto, mantenga la libertad de los partidos respecto al Estado y sus vínculos con la sociedad (Doublet, 1991 y 1993). Por otras razones, en Italia la financiación a través de subvenciones directas ha sido suprimida en dos ocasiones: mediante referéndum abrogatorio celebrado el 18 de abril de 1993 (con un $90 \%$ de votos a favor de la derogación de las leyes que la preveían) y, más recientemente, por Decreto-ley de 28 de diciembre de 2013, n. 149.

4 Adicionalmente se establece que, cuando se inicie un proceso de ilegalización, el Ministerio del Interior puede solicitar a la autoridad judicial que adopte, como medida cautelar, la suspensión de la entrega de cualquier recurso procedente de una institución pública (art. 3.5). No las pueden recibir las formaciones políticas que no estén al corriente de obligaciones tributarias y con la Seguridad social (art. 3.7) ni las que no hayan publicado sus cuentas en internet, en los términos que luego se señalarán.

${ }^{5}$ A diferencia de lo que ocurre en Alemania o en las elecciones primarias para la Presidencia de Estados Unidos, donde está previsto que la entrega de fondos públicos se vincule a la capacidad de recaudar donaciones de particulares ('matching funds'). También en Estados Unidos se prevé la creación de un 'presidential election campaign fund', integrado por una cantidad fija por cada contribuyente que, con carácter voluntario, indique que se dedique a ese fin, pero sin que, al contrario de lo que dice Ariño (2009: 22), se pueda señalar la fuerza política a la que irá destinada esa aportación; últimamente no han recurrido los candidatos a este fondo porque disfrutar de esta financiación pública era incompatible con recibir donaciones privadas: a la vista de la descomunal capacidad recaudatoria desplegada por los candidatos presidenciales en las últimas elecciones, obtienen por esta vía recursos muchísimo más elevados (además, recibir la financiación pública implica también no rebasar ciertos límites de gastos de campaña). 
dificultar la renovación de la representación y por tanto contribuir al mantenimiento de un determinado sistema de partidos ${ }^{6}$.

b) En la misma línea, aunque es lógico distinguir en función de los resultados, ya que no todas las fuerzas políticas contribuyen de la misma manera al funcionamiento del sistema, el reparto también tiene en cuenta, aunque sea en la fracción menor, el número de escaños obtenidos, lo que viene a reducir la cantidad que hayan de recibir aquellas formaciones políticas perjudicadas por la aplicación del sistema electoral previsto para el Congreso de los Diputados, caracterizado por generar notables desequilibrios en la representación, a favor de los partidos más votados $\mathrm{y}$, sobre todo, en perjuicio de algunos partidos menores, que en algunas ocasiones han sido muy notables ${ }^{7}$.

Asimismo, de forma lógica si se tiene en cuenta el carácter compuesto del Estado, se prevé que, con este mismo carácter anual, puedan otorgar subvenciones comunidades autónomas y territorios históricos vascos, atendiendo en ese caso a los mismos criterios que el Estado (art. 3.3): han de estar previstas en los correspondientes presupuestos generales, sólo pueden beneficiar a las formaciones que cuentan con representación en la asamblea o junta y se distribuyen en función de los votos y escaños obtenidos ${ }^{8}$.

\subsection{Subvenciones a los grupos}

Junto a ésta financiación ordinaria, la LOFPP prevé también, pero sin llegar a regularlas, que los poderes públicos realicen aportaciones destinadas a financiar otros gastos: en primer lugar, los de los grupos parlamentarios (en las Cortes Generales, en las asambleas de las comunidades autónomas o en las juntas generales de territorios históricos) o los de instituciones locales, de acuerdo a las normas de cada una de estas cámaras o corporaciones locales (art. 2.1.e). Respecto a los primeros, puede bastar a título de ejemplo mencionar las previsiones del Reglamento del Congreso de los Diputados (RCD), que establece una subvención fija idéntica para todos y otra variable en función del número de miembros de cada uno de ellos (en este ámbito, al contrario que en las subvenciones anuales y en las subvenciones electorales que se tratan a continuación, sí que resulta razonable tener en cuenta los escaños que han obtenido los partidos), en cuantía fijada por la Mesa, de la que deberán llevar los grupos parlamentarios una contabilidad específica, que pondrán a disposición de la

\footnotetext{
${ }^{6}$ Con el riesgo que señalan Rodríguez Teruel, Baras, Barberà y Barrio (2013: 85): al no incentivar la renovación de los partidos, las nuevas demandas sociales pasan a canalizarse por formaciones políticas al margen del sistema (y en muchas ocasiones, contrarias al sistema).

${ }^{7}$ Al menos, este tratamiento se corrigió en parte con la aprobación de la vigente LOFPP, pues la Ley orgánica 3/1987 no tenía tampoco en cuenta los votos recibidos en las circunscripciones donde no se hubiera rebasado el $3 \%$ de los sufragios que se establece en la LOREG como barrera electoral. El establecimiento de requisitos de este tipo, más concretamente el de superar un determinado porcentaje de votos, fue juzgado inconstitucional en Alemania (Sentencia de 3 de diciembre de 1968, BVerfGE 24, 300) y en Francia (DCC 89-271, de 11 de enero de 1990), por contrariar el principio de igualdad de oportunidades o limitar el pluralismo político: de ahí que tuviera que ser rebajado del $2,5 \%$ o del $5 \%$ inicialmente previsto, respectivamente, al 0,5, que se entendió acreditaba un mínimo apoyo social, una contribución al debate político aun sin representación.

${ }^{8}$ Sólo una comunidad autónoma, Galicia, ha aprobado una ley propia de carácter general sobre la materia (Ley $9 / 2015$, de 7 de agosto, de financiación de las formaciones políticas y de las fundaciones y entidades vinculadas o dependientes de ellas), que recoge también la financiación electoral en los términos que ahora se señalarán. Las demás, cuando han otorgado este tipo de subvenciones (País Vasco y Comunidad Valenciana en 2013), se han limitado a consignarlas en la correspondiente ley de presupuestos.
} 
Mesa siempre que ésta lo pida (art. $28 \mathrm{RCD})^{9}$. También tiene que integrarse en la contabilidad anual de los partidos que, como luego se verá, han de presentar ante el Tribunal de Cuentas, pero esto no significa necesariamente que haya que considerar que su destinatario, quien decide sobre estas subvenciones, es directamente el partido y no el grupo, como sostiene por ejemplo Ariño (2009: 47), si bien la falta de publicidad sobre el control que realizan los órganos de dirección de las cámaras (si es que lo hay) impide esclarecer totalmente este asunto.

Ante el número creciente de ayuntamientos y diputaciones provinciales que venían reconociendo el disfrute de fondos consignados en los presupuestos de estas corporaciones a los grupos que forman concejales o diputados provinciales en su seno, la Ley de bases del régimen local (modificada por Ley 11/1999) reguló algunos aspectos de ese tipo de contribuciones, de modo que, conforme a su art. 73.3, la dotación económica que pueden recibir los grupos políticos locales esté integrada (dentro de los límites que deberían establecerse con carácter general en las leyes de presupuestos generales del Estado, pero que nunca se han llegado a regular) por un componente fijo (idéntico para todos los grupos) y un componente variable, en función del número de miembros de cada uno de ellos, prohibiendo que se destinen al pago de remuneraciones de personal de cualquier tipo al servicio de la corporación o a adquisición de bienes que puedan constituir activos fijos de carácter patrimonial. De esta dotación deberán llevar los grupos políticos una contabilidad específica, que pondrán a disposición del pleno de la corporación siempre que éste lo pida (sin perjuicio evidentemente de su fiscalización por el Tribunal de Cuentas).

2.3. Subvenciones por gastos electorales y otras contribuciones (indirectas) en periodo electoral

Previstas en la LOREG y también en las normas electorales autonómicas, pues, como ocurre en la mayor parte de los elementos que integran el Derecho electoral español, algunas de las previsiones de la LOREG sobre subvenciones y gastos electorales tienen un carácter general y se aplican por tanto de manera uniforme a todas las elecciones que se celebran por sufragio universal, con la necesaria concreción que en algún caso es necesario establecer en la regulación específica de cada proceso (no es idéntica la cuantía de las subvenciones, por ejemplo); esta concreción está incluida también en la LOREG excepto en lo relativo a las elecciones autonómicas, puesto que ésta es una de las materia en las que las leyes electorales de cada comunidad autónoma pueden establecer algunas reglas propias, si bien su margen (conforme a lo establecido en la disposición adicional primera LOREG) no es muy amplio y tampoco lo han aprovechado, pues todas menos Cataluña, que no ha aprobado aún su ley electoral, por lo que regula estas cuestiones mediante decretos aprobados para cada convocatoria, con grave merma del principio de legalidad- han optado por mantener un gran paralelismo entre sí y con la propia LOREG (Pajares, 2004; Gavara, 2009) ${ }^{10}$.

\footnotetext{
${ }^{9}$ Aunque no se trata exactamente del mismo supuesto de subvención a grupos parlamentarios, al menos es necesario dejar constancia de normas en el ámbito de la Unión Europea sobre la materia, contenidas en el Reglamento (UE, EURATOM) No 1141/2014 del Parlamento Europeo y del Consejo, de 22 de octubre de 2014, sobre el estatuto y la financiación de los partidos políticos europeos y las fundaciones políticas europeas, asunto que ha analizado con detalle López de la Fuente (2014).

${ }^{10}$ Por esa razón, lo que se diga a continuación en materia de financiación electoral se va a corresponder con esas previsiones generales (que figuran en el título I LOREG y, más concretamente, en su capítulo VII, "Gastos y subvenciones electorales", artículos 121 a 134) y, en su caso, con las específicas de las elecciones al Congreso de los Diputados y al Senado (que figuran en el título II LOREG, en concreto en los artículos 174 y 175).
} 
Al igual que ocurre con las anuales, sólo pueden acceder a esas subvenciones destinadas a compensar los gastos de la campaña electoral las formaciones que hayan obtenido representación (art. 175.1 LOREG), aunque para recibir las subvenciones por envíos postales es necesario alcanzar resultados cualificados (como puede ser que la formación política tenga el número de escaños suficientes para constituir un grupo parlamentario o un determinado porcentaje de votos: el primero es el que ha establecido el art. 175.3).

A diferencia de la LOFPP, las leyes electorales sí que prevén las cantidades que se van a percibir, de lo que se deduce que esta actividad sí que se puede cuantificar: así, 21.167,64 € por cada escaño obtenido en el Congreso de los Diputados o en el Senado, 0,81 € por cada uno de los votos conseguidos por cada candidatura al Congreso uno de cuyos miembros, al menos, hubiera obtenido escaño de diputado, $0,32 €$ por cada uno de los votos conseguidos por cada candidato que hubiera obtenido escaño de senador y $0,18 €$ por elector en cada una de las circunscripciones en las que haya presentado lista al Congreso de los Diputados y al Senado al que hayan hecho un envío directo y personal de sobres y papeletas electorales o de propaganda y publicidad electoral (art. 175.1 y 3$)^{11}$.

En todo caso, la cantidad que finalmente reciba una formación política puede ser inferior a la suma del total que resulte de multiplicar votos y escaños por esas cantidades, ya que la subvención no podrá sobrepasar la cifra de gastos electorales declarados por cada grupo político y justificados por el Tribunal de Cuentas en el ejercicio de su función fiscalizadora (art. 127.1), lo que otorga un carácter claramente reembolsatorio a estas subvenciones: nunca se ingresará más que lo que se haya declarado y justificado gastar (Pajares, 1998: 234-235).

Con la salvedad de alguna ley autonómica, que establece como requisito para acceder a estas subvenciones electorales el obtener un determinado porcentaje de votos y no el de haber conseguido representación (tanto el art. 22 LECMad como el 41 LEVal exigen haber obtenido al menos el $3 \%$ de los votos en todo el territorio de la respectiva comunidad), cabe reiterar en este punto las mismas observaciones apuntadas anteriormente, pero acentuadas porque tendrían menos justificación: quedan excluidas las formaciones extraparlamentarias (si su objeto es compensar el esfuerzo realizado por quienes concurren al proceso electoral, la contribución a formar la voluntad popular se puede haber producido aun sin tener éxito electoral) y se trata de forma diferente a formaciones que van a ver retribuidos todos o prácticamente todos los votos recibidos (pues alcanzan escaños en la mayor parte de las circunscripciones en las que concurren) mientras otras, por tener representación en un número reducido de distritos, no van a ver computados un número incluso muy importante de votos.

Tratamiento particular merece la subvención por envíos postales de sobres, papeletas y propaganda (art. 173.3 LOREG): en primer lugar, porque es el único gasto que se reembolsa con carácter específico y, precisamente por esa razón, tiene un carácter estrictamente igualitario en la medida en que no se parte de los resultados obtenidos por las formaciones sino de la actividad realizada, por lo que si todas han hecho el mismo número de envíos recibirán igual subvención (salvo que se prevea, como hacen algunas leyes electorales autonómicas y también la LOREG en las elecciones al Parlamento Europeo, cantidades diferentes en función del

\footnotetext{
${ }^{11}$ Las cantidades relativas a gastos y subvenciones electorales se expresan en la LOREG en euros constantes (art. 131.1 y 175.4), por lo que tienen que ser actualizadas para cada convocatoria: vid. la Orden (Hacienda y Administraciones Públicas) 2272/2015, de 30 de octubre, por la que se fijan las cantidades de las subvenciones a los gastos originados por actividades electorales para las elecciones generales de 20 de diciembre de 2015 .
} 
porcentaje de votos obtenidos); por esa razón, en segundo lugar, los requisitos de acceso son más exigentes (como ya se apuntó, en las elecciones a Cortes Generales se exige contar con el número de escaños y votos suficiente para formar grupo, redacción un tanto tortuosa que podría entenderse como no equivalente al hecho mismo de llegar a formarlo, con el diferente trato que tendría en ese caso que dos o más formaciones sumen sus parlamentarios para formarlo, como ha ocurrido en alguna legislatura), con el inconveniente que puede presentar que se lleven a cabo los envíos confiando en formar grupo y luego los resultados no lo permitan, lo que no sólo impedirá recibir la subvención sino que también implicará que esos gastos sí se tengan en cuenta para comprobar que la formación ha superado o no el límite de gastos. Otra cosa es que esa actividad sea tan importante como para haber previsto esta subvención específica, que no lo parece ni en lo que a la determinación del voto ni en la preservación del sufragio libre o secreto se refiere. Quizá habría que plantearse otras alternativas, como el uso de una sola papeleta en la que figuren todas las formaciones políticas y, en su caso, quienes las integren.

Aunque las subvenciones, lógicamente, no se entregan hasta que concluyan las elecciones, tras su convocatoria y antes de que comience formalmente la campaña pueden recibir un adelanto los partidos que hubieran obtenido representantes en las últimas elecciones equivalentes, adelanto que no podrá exceder del $30 \%$ de la subvención percibida en tales elecciones, una manifestación más, a juicio de Iglesias (2016: 131) de carácter "cerrado" de este sistema de financiación, pues sólo lo reciben las formaciones parlamentarias. La cantidad recibida en este concepto se descontará de la subvención que finalmente corresponda a cada partido o se devolverá en la cuantía en que supere el importe de esta última (art. 127 bis).

Todavía en materia electoral, hay que prestar una mínima atención a ciertas disposiciones de la LOREG sobre campaña, en tanto dan lugar a una financiación pública indirecta al facilitar el uso de medios públicos para realizar actividades de campaña (Pajares, 1998: 162ss), puesto que se prevé que:

a) Los ayuntamientos han de ceder espacios para colocar propaganda electoral y locales y lugares públicos para la celebración de actos electorales (art. 54 a 57): los primeros se distribuyen en función del número de votos obtenidos en la anterior convocatoria electoral del mismo alcance, mientras que al uso de los segundos se accede, de acuerdo al principio de igualdad de oportunidades, previa petición, de modo que sólo si coinciden varias solicitudes se atenderá al criterio del número de votos.

b) Existen tarifas postales reducidas para los envíos postales de propaganda electoral (art. 59), fijadas por orden ministerial: son las mismas que se establecieron por Orden (Presidencia del Gobierno) de 3 de mayo de 1977 para las primeras elecciones democráticas, de modo que tienen un coste ínfimo $(0,006 €)$, si bien se ha entendido que están limitadas a un solo envío por elector y por un máximo de 50 gramos; fuera de estos límites se pueden realizar los envíos que se deseen, pero con las tarifas normalizadas.

c) Los medios de comunicación de titularidad pública han de ceder espacios gratuitos de propaganda electoral (art. 60 a 65 y 67): para disfrutar de tales espacios se tiene en cuenta el número de circunscripciones en que concurra cada formación política, de modo que en las elecciones a Cortes Generales es necesario presentar candidatura en un $75 \%$ de las circunscripciones, con previsiones especiales para los partidos de ámbito territorial limitado; aunque se abre a formaciones extraparlamentarias, no todas gozan del mismo tiempo, pues se prevé un baremo en 
función de los votos obtenidos en la anterior convocatoria, de modo que puede oscilar entre 45 y 10 minutos; aunque corresponde a la Junta Electoral Central distribuir estos espacios, los horarios y el orden de emisión se deciden por acuerdo entre los partidos con representación en el Congreso de los Diputados ${ }^{12}$.

\subsection{Subvenciones por gastos de campañas de referéndum}

Aunque están expresamente mencionadas también en el art. 2.1.d LOFPP, no existe en la vigente Ley orgánica $2 / 1980$, de 18 de enero, sobre regulación de las distintas modalidades de referéndum una regulación de esta cuestión (lo que no ha de extrañar a la vista de la escasísima práctica de este instrumento de democracia directa). Por esa razón, en los últimos referéndums convocados se otorgaron unas "ayudas extraordinarias para las actividades de explicación y divulgación pública" del objeto de esas votaciones, esto es, el Tratado por el que se establece una Constitución para Europa o la reforma de estatutos de autonomía, que se distribuyeron entre las formaciones políticas con representación parlamentaria de acuerdo a sus resultados electorales, sin que las normas que las regulaban, de rango infralegal, establecieran ningún vínculo entre esas actividades y el referéndum, que ni siquiera llegaba a mencionarse (Pajares, 2008: 770ss) ${ }^{13}$.

\subsection{Subvenciones a fundaciones vinculadas a partidos políticos}

Esto no agota sin embargo las posibles aportaciones de origen público, puesto que la LOFPP también regula, en la disposición adicional séptima, el régimen de las fundaciones vinculadas a partidos políticos: objeto de un tratamiento mucho más extenso tras la aprobación de la Ley orgánica 3/2015 (que ha introducido por ejemplo los requisitos para entender que existen esos vínculos así como su inscripción en el Registro de Partidos Políticos), ya con anterioridad recibían subvenciones procedentes de los presupuestos de las distintas administraciones públicas, en su caso, mediante las correspondientes convocatorias públicas, otorgadas para que puedan cumplir con sus funciones de formación y de divulgación de su ideología, a repartir conforme a la representación de la formación política a la que esté vinculada. Este criterio, junto con otros más importantes que se verán posteriormente, abona que se equiparara su régimen de financiación al previsto para los partidos de los que dependen ${ }^{14}$.

\footnotetext{
${ }^{12}$ Cabe apuntar también, en cuanto pudiera suponer de ventaja para la formación política en el poder, que el art. 50.2 y 3 prohíbe, desde la convocatoria de las elecciones y hasta su celebración, que los poderes públicos organicen o financien, directa o indirectamente, cualquier acto que contenga alusiones a las realizaciones o a los logros obtenidos, o que utilice imágenes o expresiones coincidentes o similares a las utilizadas en sus propias campañas por alguna de las entidades políticas concurrentes a las elecciones, así como realizar cualquier acto de inauguración de obras o servicios públicos o proyectos de éstos, cualquiera que sea la denominación utilizada, sin perjuicio de que dichas obras o servicios puedan entrar en funcionamiento en dicho periodo (Gálvez, 2010). También está prohibido que sujetos diferentes a partidos y candidatos hagan campaña (art. 50.5), a diferencia de lo que ocurre por ejemplo en EEUU, en cuyas elecciones numerosos grupos, organizados en PAC ('political action committee') tienen una muy destacada intervención, financiando con fondos muy abundantes campañas favorables y, sobre todo, contrarias a los candidatos en liza, en lo que el Tribunal Supremo (Citizen United v. Federal Election Commission, 558 U.S. 310) ha considerado una manifestación de la libertad de expresión constitucionalmente garantizada, infringida por las leyes que han intentado limitar estas actividades (Valero, 2012).

${ }^{13}$ Vid. Real decreto $6 / 2005$, de 14 de enero, en relación con el referéndum sobre la Constitución Europea.

14 Puede verse un ejemplo de estas subvenciones en la Orden (Educación, Cultura y Deporte) $542 / 2015$, de 4 de marzo, por la que se convocan subvenciones para gastos de funcionamiento de fundaciones y asociaciones vinculadas con partidos políticos con representación en las Cortes Generales, que realicen actividades de estudio y desarrollo del pensamiento político, social y cultural, correspondientes a 2015.
} 
La aplicación de todas estas reglas, de acuerdo con los datos que figuran en el informe del Tribunal de Cuentas sobre la contabilidad de los partidos políticos correspondiente a 2013, ha supuesto que las formaciones políticas recibieron ese año algo más de 196 millones de euros en concepto de subvenciones, de los cuales corresponden a subvenciones anuales algo más de 60 (unos 55 estatales y otros 5 de las dos comunidades que también las otorgaron, País Vasco y Comunidad Valenciana), mientras que el resto, por encima de los 135 millones, corresponde a subvenciones de grupos parlamentarios y políticos (16 de las Cortes Generales, 65 de las asambleas legislativas autonómicas y 53 de entidades locales). En realidad, por tanto, la parte principal, más de dos tercios, de las subvenciones públicas tiene como objeto el sostenimiento de estos grupos, con cargo a los presupuestos de las respectivas instituciones, lo que proporciona a las propias fuerzas políticas beneficiarias mayor capacidad de decisión sobre el importe y el reparto, pues tienen que aplicar normas mucho menos precisas que las que regulan las subvenciones anuales para el funcionamiento de partidos [lo que puede generar, según Sánchez Muñoz (2013: 169), que en algunas instituciones se utilice de forma partidista].

Todas en realidad se otorgan sin mayor requisito que el de la aprobación en los correspondientes presupuestos, con una liberalidad prácticamente absoluta, que debería reconsiderarse máxime cuando corresponde adoptarlas a quien las va a recibir. Como señalan Rodríguez Teruel, Baras, Barberà y Barrio (2013: 84), implica llevar hasta sus últimas consecuencias esa condición de "regulador regulado": esto es, los partidos no sólo establecen las reglas de su financiación, sino también la cuantía de la contribución pública, que es su fuente principal de recursos económicos. Sólo en los últimos ejercicios cabe registrar un descenso en su importe total, iniciado con la Ley orgánica $5 / 2012$, que fijaba directamente la cantidad para ese año, lo que implicaba una reducción en un $20 \%$ respecto al año anterior. En sentido contrario y hablando en términos generales, la aprobación de las leyes sobre financiación en 1987 y 2007 vino acompañada de importantes incrementos, contenido en esta última ocasión también en el propio texto legal ${ }^{15}$.

En definitiva, hay que coincidir con Iglesias (2016: 126-127) cuando señala que es una manifestación muy clara de la opción por la "hiperestabilidad", puede que explicable en el contexto de la transición política, pero con mucho menos fundamento cuando el sistema está asentado, aunque sin olvidar algún efecto positivo, señalado por Rodríguez Teruel, Baras, Barberà y Barrio (2013: 75-77): ha permitido la profesionalización de los partidos, que así han podido cumplir con las funciones constitucionalmente asignadas.

Hay que aclarar que se ofrecen las cantidades de 2013 porque es el último informe disponible, ya que la información completa sobre las subvenciones recibidas sólo se puede conocer de forma conjunta una vez que el Tribunal de Cuentas publica sus informes anuales, si bien las entregas trimestrales de las subvenciones estatales se publican en el Boletín Oficial del Estado y, tras la última reforma de la LOFPP de 2015, se ha establecido para todos los organismos y administraciones públicas que concedan subvenciones a los partidos políticos la obligación de hacer público el detalle de las abonadas y de los perceptores al menos una vez al año, en

\footnotetext{
15 Sostienen Maroto, Anderica, Baleato y Ongil (2013: 20) que en realidad todas las reformas han buscado esa finalidad de aumentar ingresos, sea aumentando posteriormente las subvenciones en la ley de presupuestos, sea favoreciendo los ingresos privados vía fundaciones, como luego se verá. En 2007 se estableció que, como mínimo, cada año había que adecuarlas al incremento del IPC, pero esta previsión se suprimió con la reforma de 2012 (mejor dicho, se mantuvo esa actualización sólo para las cantidades que se utilizan como límite en materia de donaciones y condonaciones de deuda, éstas a su vez suprimidas en 2015). Ofrece datos de la evolución de las subvenciones Ariño (2009: 39 y ss.), que concluye afirmando que son un "saqueo al contribuyente".
} 
aplicación de la Ley 19/2013, de 9 de diciembre, de transparencia, acceso a la información pública y buen gobierno, a la que se alude expresamente (sólo en esta ocasión, por cierto) en la LOFPP (en concreto, en su art. 3.9). En 2013 no hubo ningún proceso electoral, por lo que hay que remitirse al informe de 2012 para encontrar datos relativos a subvenciones electorales: el importe correspondiente a este concepto en relación a las elecciones a Cortes Generales de 20 de noviembre de 2011 fue de algo más de 34 millones de euros, cantidad en la que no aparecen desglosadas las subvenciones por envíos ${ }^{16}$.

\section{Algunos gastos (electorales) prohibidos y limitados}

En conexión, en los términos ya apuntados, con la financiación electoral, pero también con otros objetivos con mayor o menor relevancia constitucional (garantizar la igualdad de oportunidades, reducir el esfuerzo económico al que se ven sujetas las formaciones electorales, propiciar un determinado tipo de campaña mediante el fomento, la limitación o la prohibición de ciertas actividades.... $)^{17}$, la LOREG limita los gastos que pueden realizar las formaciones políticas que concurran a las elecciones (art. 131.1), mediante normas que:

a) Permiten establecer, inicialmente, el límite para cada formación, que se calcula multiplicando el número de habitantes de las circunscripciones en que concurra por una cantidad establecida legalmente (en las elecciones a Cortes Generales, según el art. 175.2, es de 0,37 €).

b) Definen qué es gasto electoral, teniendo en cuenta criterios temporales y materiales (art. 130): sólo tendrán esa consideración los realizados desde la convocatoria hasta la votación (es decir, durante un total de algo menos de 2 meses, aunque la campaña electoral dura 15 días) y, de manera abierta, los necesarios para la organización y funcionamiento de las oficinas y servicios precisos para las elecciones: en realidad, hay una enumeración de los fines a los que deben destinarse (confección de sobres y papeletas electorales, propaganda y publicidad directa o indirectamente dirigida a promover el voto, alquiler de locales para la

\footnotetext{
${ }^{16}$ En el Portal de la Transparencia del Gobierno figuran las subvenciones por gastos ordinarios (funcionamiento y seguridad) entregadas durante 2015 con cargo a los presupuestos generales del Estado (http://transparencia.gob.es/serviciosbuscador/contenido/subvencionpartido.htm?id=SubvPartidoPolitico2015\&lang=es [fecha de consulta: 1 de marzo de 2016]), pero ya no es posible consultar las del ejercicio anterior, que en su momento estuvieron disponibles: es de esperar que en el futuro esa información se vaya acumulando y no desaparezca con el nuevo año; en todo caso, para conocer el volumen de las aportaciones públicas por esta vía habría que revisar las páginas de todas las Administraciones subvencionadoras, esto es, la estatal, las autonómicas y las de decenas de diputaciones y miles de ayuntamientos, junto con las de todos los parlamentos, Cortes Generales y asambleas legislativas de comunidades autónomas: por esa razón, en la práctica, sólo es operativo esperar al informe anual del Tribunal de Cuentas. Los informes se pueden consultar en la página del Tribunal de Cuentas: http://www.tcu.es/repositorio/f1cbbbb047ad-4b61-8369-c55b0189c010/l1042.pdf (2012 [fecha de consulta: 1 de marzo de 2016]) y http://www.tcu.es/repositorio/1a904845-b3e7-4532-b9c3-3dc48de03bbc/l1108.pdf (2013 [fecha de consulta: 1 de marzo de 2016]).

${ }^{17} \mathrm{Y}$ sin que hayan dado lugar apenas a debatir sobre su compatibilidad con ciertas normas constitucionales, sobre todo a partir de las restricciones que suponen para el ejercicio de la libertad de expresión, al reducir la capacidad de intervenir en campaña: en ese sentido se pronunció el Tribunal Supremo de Estados Unidos en su Sentencia de 30 de enero de 1976 (Buckley v. Valeo, 424 U.S. 1), al entender que ciertas limitaciones suponían una restricción intolerable de la comunicación política, en cuanto en una sociedad libre sólo el pueblo debe retener el control sobre la discusión en una campaña electoral, sin que pueda el Estado reducir el número de temas públicos, disminuir la profundidad del debate o restringir la audiencia a la que alcance. Este principio tenía una salvedad en las elecciones presidenciales, porque estos procesos contaban con financiación pública (si los candidatos la aceptaban, como se indicó), de modo que era también voluntario quedar sometido a estos límites (Del Castillo, 1985: 25-27).
} 
celebración de actos de campaña electoral, remuneraciones o gratificaciones al personal no permanente que presta sus servicios a las candidaturas, medios de transporte y gastos de desplazamiento de los candidatos, dirigentes de las formaciones y personal al servicio de la candidatura), pero el último rubro de esa relación contiene esa mención genérica y abierta, por lo que en su caso habrá que acreditar esa condición ante el Tribunal de Cuentas ${ }^{18}$.

c) Establecen prohibiciones y límites específicos para algunos gastos de propaganda concretos: la contratación de publicidad sólo es posible en prensa y radios privadas, no en televisiones (públicas o privadas) ni en los restantes medios públicos de comunicación (art. 60.1); ni a esa publicidad en (algunos) medios de comunicación privados (art. 58.1) ni a "publicidad exterior" (art. 55.3, que precisa que es la realizada mediante carteles, pancartas...) podrán destinar más del $20 \%$ de límite total de gastos las formaciones electorales (límites a los que se tendría que adecuar, a juicio del Tribunal de Cuentas, la contratación de publicidad en medios electrónicos: a estas alturas, la LOREG ignora casi por completo el recurso a las nuevas tecnologías digitales para hacer campaña) ${ }^{19}$.

d) Excluyen de esa cantidad global que opera como límite de gastos los generados por el envío directo y personal a los electores de sobres y papeletas electorales o de propaganda y publicidad electoral, objeto de una subvención específica, siempre que se haya justificado la realización efectiva de esta actividad y se alcancen los resultados precisos para recibir la subvención (no suele bastar con obtener representación, como se dijo): en caso contrario, sí que se tienen en cuenta para estimar si se ha rebasado o no el límite máximo (art. 175.3.b).

e) En el caso de que se celebren simultáneamente dos o más elecciones, las formaciones políticas que concurran a esos diversos procesos coincidentes no podrán realizar gastos electorales suplementarios en cuantía superior en un $25 \%$ de los máximos permitidos para las elecciones a Cortes Generales (art. 131.2).

Como la aplicación de estas normas puede resultar algo complicada en algunos procesos electorales, la disposición adicional decimoséptima LOFPP (curiosamente, no se regula en la LOREG) establece que el Tribunal de Cuentas (cuando sea competente en la fiscalización del proceso electoral convocado) comunicará la cifra máxima individualizada de gasto electoral correspondiente a cada una de las formaciones políticas concurrentes con representación en el Congreso de los Diputados inmediatamente después de que el acuerdo de proclamación de candidaturas sea firme, lo que hasta ahora no ha hecho en los dos procesos electorales convocados tras la reforma de 2015 que introdujo esta novedad $^{20}$.

\footnotetext{
${ }^{18}$ Que ha tendido a interpretar restrictivamente esa relación, negando por ejemplo esa calificación a gastos de encuestas electorales o de restauración en el informe sobre las elecciones a Cortes Generales de 20 de noviembre de 2011 (http://www.tcu.es/repositorio/0f4a3593-b3be-43d5-a146777bed776301/1967.pdf [fecha de consulta: 1 de marzo de 2016]).

${ }^{19}$ También en el informe sobre las elecciones a Cortes Generales de 20 de noviembre de 2011.

${ }^{20}$ La medida puede ser necesaria, a fin de tener constancia previa de cuál es el límite concreto para cada formación y ajustar a esta previsión sus actividades de campaña y sus gastos, lo que resulta especialmente complicado en supuestos de concurrencia de elecciones, como ocurrió en mayo de 2015 (municipales en toda España, autonómicas en 13 comunidades, forales en el País Vasco...), en las que es posible que los partidos no concurran en todas las circunscripciones, en unas lo hagan en solitario y en otras en coaliciones que pueden estar integradas de forma diversa... A título orientativo, teniendo en cuenta los datos que recoge el informe del Tribunal de Cuentas sobre las elecciones a Cortes Generales de 20 de noviembre de 2011, una formación política que hubiera concurrido en todas las circunscripciones habría tenido como límite máximo de gastos en esa convocatoria una cantidad algo superior a los 15 millones de euros.
} 
No es obligatorio que las formaciones políticas presenten un presupuesto de su campaña al inicio del periodo electoral ni que informen de sus gastos durante el transcurso de este proceso, pues sólo tendrá lugar un control al hilo de la posterior fiscalización de su contabilidad electoral, sobre la base de los gastos declarados por las propias formaciones (que por lo tanto pueden no incluirlos ante el riesgo de incurrir en alguna infracción por rebasar el límite). Con todo, a pesar de todas estas medidas restrictivas, conforme a las cifras proporcionadas por Iglesias (2016: 135) el gasto total en las elecciones a Cortes Generales de 20 de noviembre de 2011 fue de 65 millones de euros, 25 de los cuales correspondían a envíos electorales.

\section{Una financiación privada muy modesta}

El resto de los recursos, tengan un carácter "propio", como las cuotas, el producto de sus actividades o la gestión de su patrimonio, o "ajeno", fruto de donaciones o créditos, plantea una serie de cuestiones de orden sustantivo, en la medida en que definen qué tipo de relaciones se pretende que establezcan partidos y candidaturas con otros sujetos diferentes al Estado capaces de contribuir a su sostenimiento económico, que le permitan mantener la libertad de actuación que les es propia y al tiempo garanticen un régimen de igualdad, fines entre los que parece haber una tensión, como señala Sánchez Muñoz (2013: 164-165): del primero resultaría más bien una posición tendente a admitirlas, mientras que del segundo se derivaría más bien una propensión a limitarlas o prohibirlas. También se podrían considerar desde una contraposición entre la participación (quiénes pueden contribuir) y la transparencia (cuánta publicidad hay que darle a estos ingresos) e incluso vincular directamente financiación pública y privada, como hace Ariño (2009: 21-28), que considera que la primera no puede tener como fin la independencia de los partidos, ya que han de depender de quienes los apoyen: más bien contribuiría a separarlos, a alejarlos de quienes debieran ser su sostén (sobre todo si no tiene límites), mientras que la privada les mantiene unidos a militantes, simpatizantes y votantes, siendo más importante que se sepa quién, cuánto y a quién se entrega dinero. En un tratamiento que resulta desigual, no está muy claro de entre todas esas perspectivas cuál se plasma en las normas sobre financiación vigentes en España, como se puede ver para cada una de las previsiones que cabe incluir en este apartado.

\subsection{Donaciones}

La regulación de esta vía de ingresos, establecida por primera vez en la Ley orgánica 3/1987, atiende a varios aspectos, de los que cabe considerar en primer lugar la necesidad de cumplir una serie de requisitos generales (art. 4.2.a LOFPP): no pueden ser finalistas, no sólo en consonancia con una financiación pública que tampoco se vincula a un objeto concreto (salvo en materia electoral y de seguridad) sino también para respetar la libertad de acción de los partidos, que no pueden estar condicionados a la voluntad de quien contribuye; han de tener un carácter nominativo; pueden entregarse en dinero o en especie (valoradas estas últimas según la Ley de mecenazgo y certificadas por el partido, haciendo constar el documento público que acredite la entrega del bien: art. 4.2.e); asimismo, son irrevocables y estarán destinadas a la realización de sus actividades propias. Por último, tienen que ser abonadas en cuentas de entidades de crédito abiertas con ese fin exclusivo y que no podrán tener otros ingresos (en caso de ingreso por error en otra cuenta, en un plazo de tres meses y con comunicación al Tribunal de Cuentas, habrán de ser traspasadas a esa cuenta específica; se entienden 
aceptadas si no han sido devueltas en ese mismo plazo), con constancia de fecha, importe e identidad del donante y expedición de certificado al donante (art. 4.2.b).

Más importante, en la medida en que podría revelar cuál es el objeto de estas normas, es que se prohíban algunas donaciones, en primer lugar, por razón del sujeto, ya que sólo pueden hacerlas personas físicas, excepto quienes, en ejercicio de una actividad económica o profesional, sean parte de un contrato vigente de los previstos en la legislación de contratos del sector público (art. 4.2.a). Se trata de uno de los cambios más importantes introducidos en 2015, puesto que hasta esa reforma también se permitían las de personas jurídicas salvo las de empresas públicas o que mediante contrato vigente prestaran servicios o realizaran obras o suministros para alguna administración pública. Se han suprimido por tanto este tipo de relaciones entre partidos y, básicamente, empresas, al entender que estas aportaciones, más que contribuir a fomentar el debate político, se otorgaban buscando un beneficio económico más o menos inmediato ('pay to play') ${ }^{21}$. La prohibición no afecta a personas físicas que no tengan la nacionalidad española, siempre que cumplan las reglas de la LOFPP y las normas sobre control de cambios y movimientos de capitales, aunque sí, obviamente, a Gobiernos u organismos públicos extranjeros (art. 7).

Con el fin de que esas contribuciones, incluso restringidas ahora sólo a personas físicas, no creen una dependencia singular respecto a ciertos sujetos, de modo que haya una pluralidad, en principio lo más amplia posible, de donantes, está asimismo limitada la cantidad máxima (actualizable según IPC) que una misma persona puede donar, salvo que sean de bienes inmuebles, en especie: según el art. 5.1.b, no podrán superar los 50.000 euros anuales, tras la rebaja introducida también en 2015, ya que antes eran 100.000 [cantidad que, si realmente se pretende propiciar esa financiación plural, individual, hay que considerar con Sánchez Muñoz (2015: 57) más bien elevada]. Además, las donaciones superiores a 25.000 euros y las de bienes inmuebles (no sujetas a límites) deben ser notificadas al Tribunal de Cuentas por los partidos en un plazo de tres meses desde su aceptación (art. 5.2). En caso de que una misma persona realice donaciones por importe superior al límite, el exceso habrá de ser devuelto o, de no ser posible, ingresado en el Tesoro, idéntico destino que tendrán las aportaciones sin identificación del sujeto que las realiza (art. 4.2.f y g).

Las donaciones, finalmente, no pueden ser anónimas (art. 5.1.a). Sobre este punto habría que recordar que la regulación anterior a la última reforma de 2015 había dado lugar a una práctica poco adecuada a la idea de transparencia: a pesar de que las formaciones políticas debían presentar una contabilidad detallada y documentada de sus respectivos ingresos y gastos al Tribunal de Cuentas, en los informes de este órgano no había figurado nunca algo parecido a una lista de donantes de cada partido, puesto que este órgano debía limitarse, en su caso, a declarar si los ingresos (y los gastos) son regulares, pero no a darles publicidad. En definitiva, su autor estaba identificado, pero no se ofrecían sus datos (a lo que no obligaba por lo demás la ley, al contrario, le impone guardar un sigilo "estricto y completo" de datos, informes o antecedentes que afecten a la intimidad de las

\footnotetext{
${ }^{21}$ Como es fácil deducir, se trata de un debate de cierta relevancia constitucional, puesto que si se entiende que las contribuciones económicas suponen participar de alguna manera en la vida política, se podría conectar con derechos fundamentales, algunos difícilmente atribuibles a personas físicas y menos a empresas, como el propio derecho de participación política, pero también con otros cuya titularidad no plantea tales problemas, como la libertad de expresión. Esto no implica desde luego que carezcan de fundamento estas prohibiciones, en la medida además que ese afán de expresar ciertas posiciones políticas puede canalizarse de forma perfectamente legítima por otros cauces e incluso de manera individual.
} 
personas: art. 19.2). Pues bien, en la actualidad, tienen que ser los propios partidos los que difundan, junto a otras informaciones sobre sus cuentas, las donaciones y legados de importe superior a 25.000 euros con referencia concreta a la identidad del donante o legatario (en los términos que establece el art. 14.8 y que más adelante se concretarán: tienen que hacerla anualmente, una vez entregada su contabilidad al Tribunal de Cuentas). Sin negar que aporta un elemento de transparencia hasta ahora ausente de la LOFPP, hay que reparar en que resulta incompleta, pues sólo afectará a donaciones muy elevadas ${ }^{22}$.

Incluso cuando en ese ejercicio todavía estaban permitidas las donaciones por personas jurídicas, en el informe del Tribunal de Cuentas correspondiente a 2013 sólo se reflejan unas donaciones al conjunto de partidos fiscalizados de algo menos de 6 millones de euros, muy inferior a las cuotas de afiliados, como luego se verá $\mathrm{y}$, desde luego, sin parangón con las cantidades recibidas con cargo a las diversas subvenciones previstas en la LOFPP. Su relevancia desde luego es escasa, pero es difícilmente conectable con las restricciones o prohibiciones (alguna de ellas no existente en ese momento), es más, un poco más adelante se dará cuenta de la existencia de ventajas fiscales para las donaciones que tampoco parecen haberse aprovechado ${ }^{23}$.

Tampoco en este punto las normas incluidas en la LOREG coinciden con las de la LOFPP: en realidad, habría que plantearse si tiene sentido que exista esta distinción, en tanto son las formaciones políticas las que organizan y corren con los gastos que supone afrontar una campaña electoral, no quienes forman parte de la candidatura a título individual. Así, en el periodo electoral sólo están prohibidas las aportaciones a las cuentas electorales de fondos provenientes de cualquier Administración o corporación pública, de empresas del sector público, de economía mixta $o$ de las que, mediante contrato vigente, prestan servicios o realizan suministros u obras para alguna Administración pública, así como las de extranjeros (art. 128). Salvo que se entendiera que las disposiciones de la LOFPP tienen

\footnotetext{
${ }^{22}$ Por dar cuenta de todos los cambios introducidos en esta materia, la primera regulación de las donaciones, introducida por Ley orgánica 3/1987, permitía las anónimas siempre que no superaran, para cada formación, el $5 \%$ de las subvenciones estatales anuales, un límite bastante generoso al que ningún partido, conforme a los datos declarados, llegó siquiera a aproximarse. No suprimida hasta la aprobación de la vigente LOFPP en 2007, esta disposición daba pie a todo tipo de irregularidades, al no tener que dar cuenta de la identidad, lo que permitía que hicieran donaciones sujetos que lo tenían prohibido o que una misma persona hiciera donaciones por un total superior al límite permitido, siempre que se formalizaran como varios actos que no infringieran aisladamente ese límite; incluso ese fraccionamiento lo podía hacer el propio partido, como parece deducirse de las actuaciones judiciales del "caso Bárcenas", llevadas a cabo con ocasión de la detección de una contabilidad paralela que llevaba el tesorero del PP: sobre este proceder resulta muy ilustrativo el esquema que recogen Maroto, Anderica, Baleato y Ongil (2013: 32).

${ }^{23}$ Se podría pensar que en realidad estas aportaciones se canalizan por vías irregulares, no son objeto de declaración al Tribunal de Cuentas ni se cumplen los mínimos requisitos formales, en definitiva, que discurre por cauces ilegales, como por lo demás acreditan los numerosos casos que han salido a la luz gracias a investigaciones periodísticas o judiciales. Sobre esta relación entre corrupción y financiación de partidos, en todo caso, cabe coincidir con Sánchez Muñoz (2013: 168-169; 2015: 53-54) en que, por una parte, no parece que la primera sea causa de la segunda, sino más bien lo contrario: habría que considerar que en el afán de lucro de algunos dirigentes políticos está el origen de las prácticas corruptas, que luego desvían parte de los fondos obtenidos a su partido y, por supuesto, establecen un sistema de comisiones abonadas a los partidos a cambio de adjudicaciones de contratos [en contra, Ridao (2014: 212-213), para quien la financiación de partidos constituye la "principal causa de corrupción política en España", afirmación que no sustenta en ninguna base objetiva]; por otra, sin olvidar que es fuente indudable de descrédito para los partidos y la política en general, no parece que un enfoque centrado exclusivamente en la lucha contra la corrupción sea el más adecuado para afrontar la elaboración de las normas sobre financiación partidista (como el citado autor advierte de manera bastante intensa en la Ley orgánica 3/2015), pues ha de atender principalmente a otros objetivos, relacionados con la posición constitucional de los partidos, su contribución a hacer efectivo el principio democrático, la participación y libre competencia...
} 
alcance general y se proyectan también sobre el periodo electoral, lo que no tendría mucha lógica, durante éste sí que podrían las personas jurídicas no incluidas en la relación anterior realizar donaciones en las cuentas electorales. De hecho, el art. 129 menciona expresamente a las personas físicas y a las jurídicas para establecer limitaciones que, en un nuevo ejemplo de divergencia entre ambas normas, resultan mucho más estrictas en cuanto a la cantidad, pues no pueden ser superiores a $10.000 €$ las aportaciones a cuentas electorales. Tampoco pueden ser anónimas (en el sentido antes apuntado: hay identificación, pero no está prevista su publicidad), puesto que quienes las realicen harán constar en el acto de la imposición su nombre, domicilio y el número de documento nacional de identidad o pasaporte, que será exhibido al correspondiente empleado de la entidad depositaria (art. 126). Todo esto en realidad para que en el informe sobre las elecciones a Cortes Generales de 20 de noviembre de 2011 apenas se reflejen, para todas las formaciones electorales, $30.000 €$ en concepto de donaciones...

Mención aparte, con esa regulación un tanto extravagante ubicada en una disposición adicional (la séptima), hay que hacer de las previsiones sobre las aportaciones que pueden recibir las fundaciones vinculadas a partidos políticos, en la medida en que no se les aplica la prohibición de superar esos $50.000 € \mathrm{ni}$ de recibirlas de personas jurídicas (aunque no de organismos o empresas públicas), con el único requisito para las que reciban de éstas de requerir acuerdo adoptado en debida forma por el órgano o representante competente, haciendo constar de forma expresa el cumplimiento de las previsiones legales y, en el caso de que sean por importe superior a 120.000 euros, de formalizarse en documento público ${ }^{24}$. A mayor abundamiento en esa posible vía abierta a canalizar por la fundación los recursos que no puede recibir el partido, no se consideran donación las entregas llevadas a cabo por una persona física o jurídica para financiar una actividad o un proyecto concreto de la fundación si se realiza "como consecuencia de un interés común personal o derivado de las actividades propias del objeto societario o estatutario de ambas entidades", siempre que se formalicen en documento público, se comuniquen al Tribunal de Cuentas en el plazo de tres meses desde su aceptación y se hagan públicas, preferentemente a través de la página electrónica de la fundación o entidad vinculada ${ }^{25}$

Como la regulación y el subsiguiente control de la financiación de las fundaciones vinculadas a los partidos es reciente, además de incompleto, apenas se pueden ofrecer datos correspondientes al ejercicio 2013, que resultan además muy desiguales, pues muchas de las fundaciones fiscalizadas no aportan ninguna información sobre este punto (de hecho, a diferencia de lo que hace con los partidos respecto a todas sus fuentes de financiación, el Tribunal no recoge específicamente a cuánto asciende el total de las donaciones recibidas), por lo que tan sólo cabe apuntar que, en su conjunto, rebasan mínimamente los 4 millones de euros. En sí misma no es cantidad exorbitante, pero puede dar pie, sin infringir la LOFPP, al uso de esta puerta trasera, como con acierto la denomina Sánchez Muñoz (2015: 61), así como a la externalización de gastos y actividades a la que se refiere Ridao (2014: 218).

\footnotetext{
${ }^{24}$ Las donaciones a fundaciones no se regularon hasta 2007: en ese momento se introdujo un límite de $150.000 €$, que ya era superior al de las donaciones a partidos, pero que fue suprimido en 2012.

${ }^{25}$ Reflejadas en los informes del Tribunal de Cuentas anteriores a 2012, en los que se consideraban donaciones sujetas al límite entonces existente, la última reforma de 2015 aporta al menos algo de transparencia, pero limitada: no hay plazo para la difusión ni se prevé sanción por incumplimiento; sobre su volumen, recoge información bastante completa Sánchez Muñoz (2015: 60).
} 


\subsection{Operaciones de crédito}

Fuente muy importante de financiación, sobre todo en periodo electoral, merecen tan sólo una breve regulación en la LOFPP, que permite a los partidos llegar a acuerdos respecto a las condiciones de la deuda que tengan con entidades de crédito, de los que se dará cuenta al Tribunal de Cuentas (la entidad financiera también los debe comunicar al Banco de España). Estos acuerdos, conforme al art. 4.4, tienen dos límites, ambos introducidos en la reforma de 2015: por un lado, el tipo de interés que se aplique no puede ser inferior al que corresponda a las condiciones de mercado. Por otro, se han prohibido las condonaciones totales 0 parciales de deuda a los partidos políticos (a estos efectos se entiende por condonación la cancelación total o parcial del principal del crédito o de los intereses vencidos o la renegociación del tipo de interés por debajo de los aplicados en condiciones de mercado). En esta última materia la regulación ha sido objeto de numerosos cambios: las condonaciones se regularon sólo a partir de 2007, pero sin establecer límite alguno más allá de que fueran admitidas "según los usos y costumbres del tráfico mercantil habitual entre las partes", por lo que simplemente se daba cobertura legal a prácticas habituales con anterioridad, cualquiera que fuera la decisión que adoptaran las entidades financieras; en 2012 se estableció una cierta restricción, al permitirlas sólo si no superaban los 100.000 euros anuales. Esta última regulación ha puesto fin por tanto a una situación sobre la que advirtieron en varias ocasiones los informes no sólo del Tribunal de Cuentas, sino también del GRECO (Grupo de Estados contra la corrupción, constituido en el seno del Consejo de Europa), que ha centrado parte de sus actividades en la financiación de los partidos: los consideraba donaciones encubiertas que eludían los límites legales, en una situación que, como mínimo, llevaba a preguntarse cuál era la razón de este generoso comportamiento por parte de las entidades bancarias, no sólo al conceder los créditos sino también al condonarlos ${ }^{26}$.

Resulta todavía más sorprendente cuando en sus informes el Tribunal de Cuentas viene advirtiendo del alto endeudamiento de las formaciones políticas (conforme a los datos que recoge el informe correspondiente a 2013, asciende a algo más de 200 millones de euros), lo que puede generar problemas de vulnerabilidad por un lado y de dependencia de las entidades de crédito por otro. Aunque se detecta una muy lenta tendencia a que este volumen de deuda vaya descendiendo, es de tal magnitud que apenas se vislumbra su reducción a cifras más adecuadas, a lo que tampoco contribuye que con la vigente LOFPP se suprimieran los límites que figuraron inicialmente en la Ley orgánica 3/1987 (las amortizaciones anuales no podían superar el $25 \%$ de las subvenciones estatales, lo que cabe preguntarse también si resultaba o no operativo). Tampoco hay pronunciamiento legal alguno sobre el valor máximo del préstamo, las entidades con las que se puede contraer, las condiciones de pago...

Dado que algunas formaciones políticas, especialmente las de reciente creación, están empezando a recurrir a vías alternativas a esta "financiarización" del sistema de partidos (Maroto, Anderica, Baleato y Ongil, 2013: 10ss), se ha introducido a resultas de la última reforma de la LOFPP una mención a los mecanismos de financiación participativa ('crowdfunding'), simplemente para considerar que les son aplicables las disposiciones generales sobre donaciones (art.

26 En concreto, los informes de 2009 y 2011, disponibles en su página electrónica: http://www.coe.int/t/dghl/monitoring/greco/evaluations/round3/GrecoEval3(2008)3 Spain_Two ES.pdf (2009 [fecha de consulta: 1 de marzo de 2016]) y http://www.coe.int/t/dghl/monitoring/greco/evaluations/round3/GrecoRC3(2011)5 Spain FR.pdf (2011 [fecha de consulta: 1 de marzo de 2016]); sobre GRECO, Ridao (2014: 212). En Ariño (2009: 56) se pueden ver algunas cifras sobre estas operaciones. 
4.2.h). Reclamada su regulación por el Tribunal de Cuentas en el informe sobre las elecciones al Parlamento Europeo de 2014, primera ocasión en la que aparecen estas prácticas reflejadas en la contabilidad electoral, responde a la voluntad de algunos partidos de adoptar una nueva organización en la que se prescinde de la figura del militante y de sus cuotas, por un lado, y de los créditos bancarios, por otro, de modo que solicitan, en los procesos electorales en los que han participado desde su reciente fundación, aportaciones de sus seguidores para hacer frente a los gastos de campaña (González y Maroto, 2015) ${ }^{27}$.

\subsection{Cuotas y aportaciones}

La LOFPP se limita a establecer que los afiliados pueden ingresarlas en cuentas específicas, distintas a las destinadas a donaciones, mediante domiciliación bancaria o ingreso nominativo (art. 8.1). Parece distinguirse entre cuotas y aportaciones (no expresamente: las primeras serían las cantidades ingresadas regularmente, a título de miembro de una asociación, mientras que las segundas serían los restantes ingresos que realizaran sus integrantes o incluso todo tipo de cargos, electos o no, si así lo hacen constar), no sólo por la obligación de mantener cuentas específicas y separadas sino porque las aportaciones superiores a $25.000 €$ y las de bienes inmuebles han de ser notificadas al Tribunal de Cuentas en tres meses desde el cierre del ejercicio (como las donaciones: art. 8.2 y 3$)^{28}$.

Sin que se puedan calificar de irrelevantes, por esta vía no alcanzan las formaciones políticas a recibir más que una cifra algo inferior a 43 millones de euros en 2013, apenas una quinta parte de lo que les supone, en su conjunto, la financiación mediante subvenciones, incluso si se suman las donaciones, esto es, el conjunto de la financiación privada. Aunque varía según los años y los partidos, el dato abona sin duda la situación de excesiva dependencia del erario público y, al tiempo, parece síntoma también de escasa conexión con quienes simpatizan o podrían apoyarlos, más allá de la mera expresión del sufragio: ni los partidos las buscan, ni los ciudadanos están interesados en participar por esta vía ${ }^{29}$. No es un problema de desafección política nacida con la crisis económica de esta década, pues su reducida cuantía es una constante; es más, casi cabría apuntar lo contrario, que en esta situación el interés por la política ha aumentado y algunos partidos surgidos recientemente, como se acaba de señalar, han desplegado una notable capacidad de captación de recursos por parte de un número amplio de electores ${ }^{30}$.

\footnotetext{
27 En el informe mencionado en el texto (http://www.tcu.es/repositorio/5c0f591c-e063-4156-a3a7bdb78f969b5d/l R1065.html.pdf [fecha de consulta: 1 de marzo de 2016]) se recogen ciertas deficiencias, debidas a la herramienta electrónica utilizada, que no permitía identificar todas las aportaciones. En todo caso, habrá que determinar en el futuro si son aportaciones a fondo perdido, por lo que les resultaría aplicable el régimen de las donaciones, o microcréditos, si es que el partido se compromete a devolverlos, si es que lo considera adecuado, porque obligación no hay: son perfectamente compatibles los diversos tipos de financiación, publica, privada y mediante créditos.

${ }^{28}$ Se pregunta Sánchez Muñoz (2013: 182) si realmente las aportaciones de cargos públicos pueden considerarse ingresos privados, cuando se hacen a costa de retribuciones pagadas por instituciones públicas.

${ }^{29}$ En los informes del Tribunal de Cuentas no se refleja ni cuántos afiliados tienen los partidos ni cuál es la cuota que deberían pagar. Ariño (2009: 48) sostiene directamente que las cuotas no se pagan sino por un número más bien reducido de militantes, sin que este hecho tenga consecuencias prácticas, mientras que Rodríguez Teruel, Baras, Barberà y Barrio (2013: 79-80) destacan la paradoja de que los partidos declaran que su militancia haya ido incrementándose (datos que, como advierten, tienen que ser tomados con cautela) al tiempo que los ingresos por cuotas han ido descendiendo.

${ }^{30}$ Se puede incentivar que los partidos se preocupen por recibir financiación de sus seguidores, incluso con fundamento constitucional: en la Sentencia de 9 de abril de 1992 (BverfGE 85, 264), ya mencionada, el Tribunal Constitucional Federal rechazó el sistema de financiación vigente en ese momento en Alemania, por considerarlo desligado de la relevancia de cada partido y contrario a la igualdad de trato: poniendo fin a la prohibición de financiación anual que se deducía de su
} 


\subsection{Otras fuentes}

En un aspecto que ha merecido cierta atención en los informes del Tribunal de Cuentas, emitidos antes y también después de introducirse esta regulación en 2007, es posible de acuerdo al art. 6 LOFPP que los partidos reciban ingresos de sus actividades propias, incluyendo aquellas que se vengan desarrollando tradicionalmente en sus sedes y faciliten el contacto y la interacción con los ciudadanos, los rendimientos procedentes de la gestión de su propio patrimonio, los beneficios procedentes de sus actividades promocionales y los que puedan obtenerse de los servicios que puedan prestar en relación con sus fines específicos (todo ello obviamente con el debido reflejo contable). Quedan prohibidas en cambio las de carácter mercantil y se obliga a identificar al transmitente cuando el partido reciba más de 300 euros: se trataría del único supuesto en el que cabe recibir ingresos sin revelar la identidad del aportante (lotería, venta de propaganda...) ${ }^{31}$.

Más relevante es la prohibición de aceptar que directa o indirectamente terceros asuman de forma efectiva el coste de sus adquisiciones de bienes, obras o servicio o cualquier otro gasto (art. 4.3), en tanto ha servido como instrumento para recibir aportaciones de las que no quedaba constancia: una empresa asume el gasto (ha sido frecuente practicarlo en campañas electorales, de modo que los carteles, el alquiler de un local, el transporte... no lo pagaba el partido sino quien participaba en la trama fraudulenta), a cambio de recibir la adjudicación de un contrato de una administración controlada por el partido por un importe superior al servicio prestado (Gürtel); también podía darse el caso de que ese tercero que asume el coste no tenga otra finalidad que ésa: facturar gastos a empresas cuya contribución al partido no debía figurar, por lo que contrataban, por ejemplo, la elaboración de informes ficticios, ingresos que luego destinaban a pagar gastos del partido (Filesa). Lógicamente, han de sancionarse como si se tratara de una donación irregular (conforme al art. 17.2.a, como luego se verá): puede serlo hasta por partida triple, ya que no hay constancia de la aportación, permite que la hagan entidades que lo tienen prohibido y que rebasen el límite fijado ${ }^{32}$.

\subsection{El régimen tributario de los partidos y de sus ingresos}

Como cierre de este apartado hay que dar cuenta de las especialidades del régimen tributario de los partidos, que les otorgan en primer lugar ciertas ventajas fiscales: están exentas de tributar en el impuesto de sociedades cuotas, subvenciones, donaciones, rendimientos de actividades propias o transmisión de bienes (siempre que el producto de la enajenación se destine a inversiones o financiación) y rendimientos del patrimonio, mientras que las rentas no exentas están sujetas a un tipo del $25 \%$ (art. 10 y 11). Por otro lado, en lo que afecta no ya a los partidos sino a quienes contribuyen, siempre que estén convenientemente acreditadas las cuotas y

jurisprudencia anterior, establece ciertos límites a las subvenciones anuales, en términos relativos: no pueden rebasar el dinero recibido en concepto de cuotas o donaciones (Doublet: 1993). Una reforma legal de 1994 estableció mecanismos de subvención ligados tanto a los votos recibidos como a estas aportaciones privadas, a fin de estimular los lazos entre los partidos y la sociedad.

${ }^{31}$ A criterio del Tribunal de Cuentas, la participación de los partidos políticos en sociedades sólo es admisible si no tienen ánimo de lucro, están preferentemente dedicadas a prestar servicios a los militantes y no sean titulares de inmuebles donde estén radicadas las sedes del partido.

${ }^{32}$ Sobre las relaciones entre partidos y empresas, la Ley orgánica 3/2015 también ha establecido una serie de criterios acerca de la contratación de los partidos, sujeta a los principios de publicidad, concurrencia, transparencia, confidencialidad, igualdad y no discriminación, sin perjuicio del respeto a la autonomía de la voluntad, debiendo cada partido aprobar unas instrucciones internas en la materia de contratación, adecuadas a esas previsiones y publicadas en su página electrónica (disposición adicional decimotercera), a pesar de lo cual le parecen a Iglesias (2016: 147) excesivamente apegadas a los criterios de contratación pública. 
aportaciones serán deducibles de la base imponible del impuesto sobre la renta de las personas físicas, con el límite de 600 euros anuales (art. 12.1); por su parte, las donaciones se benefician de las deducciones previstas en la Ley de mecenazgo (art. 12.2), que en la actualidad establece que, si el importe no supera los $150 €$, la deducción de la cuota del impuesto sobre la renta de las personas físicas será del $75 \%$; por encima de esa cantidad, un $30 \%$, que se eleva al $35 \%$ cuando los donativos se haya hecho por la misma persona a la misma entidad durante los últimos tres años, estimulando a su vez la fidelidad (art. 19 de la Ley 49/2002, de 23 de diciembre, de régimen fiscal de las entidades sin fines lucrativos y de los incentivos fiscales al mecenazgo $)^{33}$.

Son sin duda estas últimas normas ventajosas, pero que parecen haber tenido poco efecto como estímulo, a la vista de las cifras recogidas en apartados anteriores, sobre todo si se tiene en cuenta que están vigentes desde 1994 (aunque sólo se incorporaron a la LOFPP en 2007: es la única parte que no tiene carácter orgánico, por lo que se puede modificar por leyes aprobadas por el procedimiento ordinario, conforme a la disposición adicional decimocuarta), quizá por el desinterés del partido en buscar estas fuentes, quizá por desconocimiento, cuando parecerían estar en una línea bastante estimable, la de que, como dice Sánchez Muñoz (2013: 192), "una parte del dinero que reciben los partidos pasa a depender en parte de los contribuyentes" ${ }^{\prime 3}$.

\section{5. ¿Un control efectivo?}

El último punto que hay que tratar afecta los instrumentos mediante los cuales se pretende controlar el cumplimiento de estas normas, aunque también puede considerarse de manera autónoma, esto es, es posible establecerlos aún en el caso de que no se dispusiera nada sobre su financiación, pública o privada, con el objeto entonces de que se pueda conocer cuáles son sus fuentes de ingresos y el destino de sus gastos, que en sí mismo parece un objeto que justifica de forma más que suficiente la introducción de este tipo de normas. En el ordenamiento español cabe incluir en este bloque las previsiones relacionadas con las obligaciones contables de las formaciones políticas, con los procedimientos de fiscalización, con la publicidad de las cuentas y con el régimen sancionador.

\subsection{Requisitos contables}

Las obligaciones de los partidos en este orden son básicamente tres: en primer lugar, llevar registros contables detallados, que permitan en todo momento conocer su situación financiera y el cumplimiento de las obligaciones legales. En el mismo

\footnotetext{
${ }^{33}$ Tampoco este aspecto es ajeno al debate constitucional, en la medida en que puede beneficiar en mayor medida a los contribuyentes de mayor renta, a su vez más tendentes a realizar donaciones a unos determinados partidos: al menos en Alemania son consideraciones que tuvo en cuenta la Sentencia 24 de junio de 1958 (BVerfGE 8,51), que abrió la puerta a las subvenciones públicas, recogidas a partir de los presupuestos federales de 1959, una vez que concluyó que el modo en que se habían establecido ciertas desgravaciones infringía el principio de igualdad.

${ }^{34}$ Los datos que ofrece la Agencia Tributaria son contundentes: en 2013 sólo en 90.045 liquidaciones se dedujeron cuotas o donaciones a partidos políticos en la declaración del impuesto sobre la renta de las personas físicas, cuando la cifra de militantes (no tanto de donantes) es muy superior: ¿es que ignoran la existencia de este trato fiscal? De acuerdo con esa información (que se puede consultar en http://www.agenciatributaria.es/AEAT/Contenidos Comunes/La Agencia Tributaria/Estadisticas/Public aciones/sites/irpf/2013/jrubik28375171ce4047764cd06715b0c1ebc8987e4fa4.html [fecha de consulta: 1 de marzo de 2016]) la afirmación de Maroto, Anderica, Baleato y Ongil (2013: 26), que destacan que casi la mitad de los que se desgravan por pertenecer a un partido político ganan más de $30.000 €$ anuales, no sería correcta (apenas suponen una tercera parte de esas declaraciones), pero sobre todo no se alcanza a saber la razón por la cual éste sería un dato significativo, en el sentido que sea.
} 
art. 14 se establece a estos efectos un contenido mínimo pero bastante detallado de los libros de tesorería, inventarios y balances (deberán contener el inventario anual de todos los bienes, la cuenta de ingresos y la de gastos y las operaciones de (apital) ${ }^{35}$.

En segundo lugar, han de prever un sistema de control interno que garantice la adecuada intervención y contabilización de todos los actos y documentos de los que se deriven derechos y obligaciones de contenido económico, conforme a sus estatutos, sin que haya un tipo o modelo único ni tampoco obligación de someterse a una auditoría externa (art. 15). La reforma de 2015 ha modificado en este punto la LOPP para introducir como contenido obligatorio de los estatutos algunos elementos relativos a su financiación: el régimen de administración, contabilidad y documentación del partido, la indicación de si cuenta con patrimonio fundacional, la procedencia de los recursos económicos, el procedimiento de rendición de cuentas y el procedimiento y el órgano competente para la aprobación de las cuentas anuales en el que se incluya la obligación de remitirlas anualmente al Tribunal de Cuentas dentro del plazo legalmente establecido (art. 3.2). En todo caso, como afirma Ariño (2009: 8), la transparencia interna es escasa, sin que esté garantizado un control en el seno del partido.

Por último, se ha introducido también por la Ley orgánica 3/2015 la obligación de que los partidos cuenten con un responsable de la gestión económicofinanciera (cargo que evidentemente ya existía) que cumpla determinados requisitos y funciones (art. 14 bis). La novedad por tanto no es tanto la introducción de esta figura, sino la regulación de estos extremos, más detallada sobre el primero de ellos, pues, además de incluir el procedimiento para designar a la persona que ocupe este puesto como parte del contenido obligatorio de los estatutos del partido, se establece que ha de contar con acreditados conocimientos o experiencia profesional en el ámbito económico, que no pueden ser funcionarios en activo y, especialmente, la concurrencia de una "condición de honorabilidad" que excluye a quienes no hayan cumplido penas privativas de libertad o cancelado los antecedentes penales relacionados con determinados delitos (falsedad, contra la libertad, contra el patrimonio y orden socioeconómico, contra la Hacienda pública y la Seguridad social, contra los derechos de los trabajadores, la Administración pública, la Constitución, las instituciones del Estado, la Administración de Justicia, la comunidad internacional, de traición y contra la paz o la independencia del Estado y relativos a la defensa nacional, y contra el orden público, en especial, el terrorismo), así como a los incursos en un proceso penal por un delito que comporte la inhabilitación o la pérdida del derecho de sufragio pasivo cuando se haya dictado auto de apertura de juicio oral y los inhabilitados conforme a la Ley concursal. Entre las segundas, le corresponde presentar las cuentas anuales y responder de ellas (incluso en el ámbito penal), con independencia de la que tengan quienes adopten las resoluciones o realicen los actos reflejados en las cuentas.

\footnotetext{
${ }^{35}$ Dado que su objeto no es precisamente de ámbito económico, conforme a las previsiones de la disposición adicional octava de la Ley orgánica $8 / 2007$, los partidos políticos habían de quedar sujetos a un plan de contabilidad específico, resultado de la adaptación que debía hacer el Tribunal de Cuentas a las características de las formaciones políticas previo análisis y debate por la Comisión mixta Congreso-Senado para las relaciones con el Tribunal de Cuentas: aunque el plazo para elaborarlo era de seis meses, el acuerdo del pleno del Tribunal que lo aprobó no se adoptó hasta el 26 de septiembre de 2013, para entrar en vigor el 1 de enero de 2014. Pues bien, la disposición transitoria segunda de la Ley orgánica 3/2015 establece que deberá ser adaptado a las nuevas previsiones legales, por lo que no vinculará hasta que el Tribunal lleve a cabo esa tarea con la adopción de un nuevo acuerdo, lo que todavía no ha ocurrido (curiosamente, con una técnica legislativa manifiestamente mejorable, en esa disposición transitoria se hace referencia expresa a la disposición adicional octava que la propia Ley orgánica 3/2015 viene a derogar). Sobre las deficiencias en materia contable, Rodríguez López y Fidalgo (2012).
} 
De forma específica para el periodo electoral, las formaciones que concurren a las elecciones deben abrir cuentas en entidades bancarias, que serán las únicas en las que se puedan hacer ingresos y de las que puedan realizar gastos, así como designar un administrador electoral responsable de sus ingresos y gastos y de su contabilidad (art. 121 a 125 LOREG).

\subsection{Procedimientos de fiscalización}

El peso del control recae en el Tribunal de Cuentas, al que le corresponde en exclusiva el control de la actividad económico-financiera de los partidos (art. 16.1 LOFPP y art. 1.1 LOTCu), calificación que no excluye por un lado el ejercicio de atribuciones por organismos autonómicos similares (sobre todo en el ámbito electoral: de hecho, fue precisamente la LOREG la primera en introducir el control por este organismo, luego extendido a la contabilidad anual de los partidos; como las subvenciones en este ámbito, en caso de elecciones autonómicas, tienen que abonarlas las comunidades autónomas, sus leyes electorales pueden atribuir la fiscalización de la contabilidad de ese periodo a sus propios órganos de control externo) ni por otro la rendición de cuentas de grupos parlamentarios y de corporaciones locales ante los órganos de gobierno de esas instituciones, de conformidad con sus propias normas.

\subsubsection{Sujetos obligados}

Siguiendo una vez más la distinción que ya se ha hecho en apartados anteriores, cabe recoger en primer lugar las previsiones de la LOFPP: todos los partidos políticos (y no sólo los que reciban subvenciones anuales del Estado o de comunidades autónomas o territorios históricos, como ocurría hasta 2015) han de presentar ante el Tribunal de Cuentas, antes del 30 de junio del año siguiente, una contabilidad detallada y documentada de sus respectivos ingresos y gastos durante el ejercicio anterior, que deberá contener el balance, la cuenta de resultados, una memoria explicativa en la que conste una relación de subvenciones y donaciones ( $y$ cualquier transacción que constituya una ventaja económica), con determinación de donante y capital recibido, y un anexo con las condiciones de los créditos o préstamos y la entidad con la que haya contratado, su importe, tipo de interés, plazo de amortización y deuda pendiente (art. 14.3 y 6).

Tal como lo han reflejado los informes del Tribunal, es complicado determinar el alcance y contenido de esta contabilidad, puesto que se trata de entidades con una organización territorial e institucional muy compleja, que siguen modelos muy heterogéneos y realizan actividades muy diversas. En particular, ha sido problemático determinar el ámbito territorial al que debía extenderse, en la medida en que se advertía la ausencia de las cuentas de las sedes locales: frente a la insistencia del Tribunal en que debían recogerse (como también se hacía en el informe GRECO 2013, advirtiendo del riesgo de facilitar prácticas corruptas, a la vista de la importancia de algunas decisiones que se adoptan a nivel municipal), la LOFPP sólo hace referencia al ámbito estatal, al autonómico y al provincial, en el cual se integrarán las cuentas correspondientes al ámbito local y comarcal, si existiese (art. 14.5): sin dejar de señalar las obvias dificultades que para los partidos puede suponer reflejar en su contabilidad la actividad de cientos o miles de agrupaciones infraprovinciales, se trata de una cláusula que no deja claro si la información que se va a poner a disposición del Tribunal tendrá un carácter 
exhaustivo, como señala Iglesias (2016: 143$)^{36}$. También ha indicado el Tribunal que hay que integrar tanto las cuentas de los grupos parlamentarios como, en caso de haber concurrido a un proceso electoral durante ese periodo, la contabilidad electoral, sin perjuicio del control que corresponda ejercer sobre ellas por el órgano competente (el parlamento que las otorga y el propio Tribunal o el órgano similar de ámbito autonómico, en su caso, para las electorales); también se recogen, como ya se dijo, subvenciones recibidas por los grupos políticos constituidos en instituciones locales.

Además, quedan sujetas a esta fiscalización las fundaciones vinculadas a los partidos políticos (disposición adicional séptima), pues se someten las aportaciones que reciban al sistema de control y fiscalización y al régimen sancionador de los partidos políticos, sin perjuicio de las normas propias que les sean de aplicación, aunque en un régimen algo diferente, que lleva a plantearse una vez más la razón de ese diferente trato entre los partidos y sus fundaciones, ya que el control del Tribunal de Cuentas se extiende a la regularidad de aportaciones y de gastos derivados de programas y actividades financiados con cargo a subvenciones públicas. Además de enviar toda la documentación al Tribunal de Cuentas, para ellas sí que se establece la obligación de realizar una auditoría de sus cuentas anuales; deben asimismo informar anualmente al Ministerio de Hacienda y Administraciones Públicas de todas las donaciones y aportaciones recibidas.

Una vez presentadas las cuentas anuales, el Tribunal de Cuentas entregará al partido político justificación de haber efectuado dicha presentación y, en el mes siguiente a la finalización del plazo de presentación de las cuentas anuales, remitirá al Registro de Partidos Políticos y a la Presidencia de la Comisión Mixta para las Relaciones con el Tribunal de Cuentas la relación de los partidos que hayan realizado la presentación, todo ello a los efectos que se indicarán al tratar de las sanciones (art. 14.7).

En cambio, la fiscalización posterior a las elecciones (conviene recordar que durante el periodo electoral las juntas electorales realizan ciertas tareas de carácter meramente administrativo: comunicación de cuentas electorales conforme al art. 124, solicitud de adelantos de subvenciones conforme al art. 127 bis...) sólo alcanza a las formaciones que hubieran alcanzado los requisitos exigidos para recibir subvenciones públicas o que hubieran solicitado adelantos con cargo a ellas, que han de presentar ante el Tribunal de Cuentas una contabilidad detallada y documentada de sus respectivos ingresos y gastos electorales (art. 133.1, todos de la LOREG).

Respecto a la obligaciones de otros sujetos, mientras se establece con claridad en la LOREG (las entidades financieras que hayan concedido créditos y las empresas que hayan facturado por gastos electorales superiores a $10.000 €$ han de enviar noticia detallada al Tribunal de Cuentas: art. 133.3 y 5), en la LOFPP tan sólo se enunciaba hasta 2015 un deber de colaboración (art. 19), a requerimiento del propio Tribunal, que podría permitir el examen de información proporcionada por entidades con relaciones económicas con los partidos, pero que no ha tenido mayor reflejo en los informes sobre la contabilidad anual. Aparte de regular con carácter general este deber de colaboración para todas las personas físicas o jurídicas, públicas o privadas, a instancias del Tribunal, la Ley orgánica 3/2015 ha modificado la LOTCu para especificar que las entidades de crédito están obligadas a identificar

\footnotetext{
${ }^{36}$ Quizá eso explique la conclusión a la que llegan Rodríguez Teruel, Baras, Barberà y Barrio (2013: 76): las normas sobre financiación han evitado el clientelismo a nivel estatal, pero no en el local o en el autonómico.
} 
las diferentes cuentas que se refieran a fondos de los partidos políticos y fundaciones y entidades vinculadas a o dependientes de ellos, así como las personas autorizadas a efectuar operaciones de disposición con cargo a dichas cuentas; más concretamente, de las cuentas en las que se ingresen cuotas, deberán aportar datos sobre saldos y movimientos en las fechas o periodos respecto de los que se solicite, sin facilitar en ningún caso los que permitan identificar a personas afiliadas a los partidos políticos, mientras que de las cuentas en las que se ingresen donaciones y otras aportaciones también se facilitará información sobre la identidad de quienes las realicen si el importe acumulado de las aportaciones en un año natural excede de $3.000 €$ (art. 7.5), todo ello en la línea de mejorar el conocimiento de las relaciones que mantienen con entidades de crédito de la que se hacía eco el informe GRECO 2013.

\subsubsection{Informes del Tribunal de Cuentas}

En uno y otro caso, la fiscalización da lugar a un informe, de carácter anual o sobre cada proceso electoral. Respecto a los del primer tipo, hay que aclarar que, aunque todos los partidos deben presentar sus cuentas anualmente, en realidad sólo se fiscalizarán obligatoriamente las de los que reciban subvenciones a cargo de presupuestos estatales o autonómicos, quedando a criterio del Tribunal de Cuentas realizar las actuaciones que estime oportunas respecto a los demás partidos (art. 16.2 LOFPP).

El alcance del control viene definido por la LOFPP en un triple ámbito, al afectar a la legalidad de los recursos públicos y privados, a la regularidad contable de actividades económico-financieras y a la adecuación de su actividad económicofinanciera a los principios de gestión financiera que sean exigibles conforme a su naturaleza (art. 16.3). Algunas facetas de este control se pueden definir con mayor claridad, sobre todo si tienen un alcance contable: que los estados reflejen la situación financiera y las operaciones económicas, que la documentación contable sea adecuada y suficientemente justificativa... Pero es más complicado que en otros aspectos alcance a ser eficaz, sobre todo por lo que se refiere a la legalidad y regularidad de ingresos privados, difícilmente fiscalizable cuando los datos en los que se basa son los proporcionados por las propias formaciones políticas.

Mención aparte ha de hacerse de la fiscalización de los gastos de seguridad, los únicos que se determinan expresamente y son objeto de una subvención específica: en este ámbito el Tribunal puede llevar un control mucho más adecuado a la técnica subvencional, en la medida en que se trata de comprobar los programas o actividades realizadas durante el ejercicio en ese ámbito, previéndose que, en caso de existir remanente, tenga que ser reintegrado (art. 22 del Real decreto 1306/2011, de 26 de septiembre, por el que se regula la tramitación de las subvenciones estatales anuales para sufragar los gastos de seguridad en que incurran los partidos políticos). El resto de los gastos (salvo los electorales, objeto de un informe específico), al no estar no determinados, no se fiscaliza, de modo que, en el caso hipotético de que un partido declarara gastos ordinarios, esto es, los no correspondientes a seguridad, inferiores a la subvención recibida, no está previsto el reingreso del remanente.

El informe sobre esta contabilidad anual debe emitirse en seis meses desde la recepción de la documentación (art. 16.4 LOFPP), plazo que no se respeta: en principio, tendría que estar concluida esa tarea al comenzar el segundo año posterior al del ejercicio que se refiere (el plazo para entregar las cuentas no concluye hasta junio y la fiscalización se desarrolla hasta diciembre), pero en algunas ocasiones ha llegado a demorarse varios años, como el informe 
correspondiente a 2008, emitido en junio de 2013... ¡Más de tres años de retraso! Aparte de otras cuestiones sobre organización y carga de trabajo del Tribunal, quizá la entrada en vigor de la Ley orgánica 8/2007 haya contribuido a dilatar de tamaña manera la emisión de ese informe, pues posteriormente ha ido acortando el tiempo que tardaba en concluirlo: en marzo de 2014 aprobó el informe correspondiente a tres ejercicios $(2009,2010$ y 2011), mientras que los de los dos últimos años fiscalizados han sido entregados con apenas seis meses de retraso, lo que tampoco puede calificarse como una actuación totalmente desviada, aunque convendría corregirla todo lo posible. Más allá de las reflexiones que se hacen al final de este apartado, habrá que constatar en el futuro los efectos que pueda tener la reforma de marzo de 2015 sobre los informes posteriores, incluyendo el correspondiente a ese mismo año, todavía no aprobado cuando se redactan estas líneas.

En el informe se dejará constancia de la regularidad y adecuación de las cuentas o, en caso contrario, de las infracciones o prácticas irregulares (art. 16.4) y se remitirá, sin perjuicio de la imposición de las sanciones de las que se trata a continuación, a la Comisión Mixta de las Cortes Generales encargada de las relaciones con este órgano (art. 16.5), a la que corresponde aprobarlo: puesto que el Tribunal de Cuentas es un órgano de fiscalización de las cuentas públicas, dependiente de las Cortes Generales, que nombran a sus doce vocales, su informe ha de ser discutido por una comisión parlamentaria, que siempre ha aceptado hasta la fecha las conclusiones recogidas en ese informe. Se trata por tanto de un modelo de control bastante próximo al parlamentario, si bien dotado de una primera fase de análisis eminentemente técnico, que marca de modo indudable el pronunciamiento de la citada comisión.

De forma coherente con la regulación de la figura, pero con un alcance absurdo, la Comisión puede acordar, en el plazo de dos meses desde la aprobación del informe y para que dé noticia sobre infracciones o prácticas irregulares, la comparecencia del responsable de la gestión económica de partidos, se dice, que reciban subvenciones electorales y no de las que estén previstas en los correspondientes presupuestos generales (art. 16 bis). Tratándose de una medida que podría tener un cierto alcance (sujeta en todo caso a las condiciones en las que se desarrolla habitualmente el control parlamentario y, más concretamente, la comparecencia de autoridades y particulares que puedan aportar información a las cámaras), se ha cometido un notable error, pues carece de sentido en un proceso que tiene como objeto la fiscalización de cuentas anuales, al que se van a someter en principio sólo las formaciones que reciben estas últimas, prever la comparecencia de los responsables de quienes reciben subvenciones electorales, ya que puede no haber identidad entre unas y otras. Habrá que esperar a su puesta en práctica para comprobar cuál es su alcance: si comparecen todos los responsables, los de las principales formaciones, sólo los de las que hayan cometido alguna infracción, si se convierte en uso habitual o resulta finalmente esporádico, si la mayoría obstaculiza estas comparecencias cuando le resulten molestas...

Respecto a la contabilidad electoral, el informe sobre su fiscalización (destinado básicamente a constatar la cantidad de gastos electorales regulares y justificados) se remite al Gobierno y a la Comisión mixta de las Cortes Generales, a la que corresponde aprobar dicho informe, conforme al cual han de cuantificarse las subvenciones (art. 134 LOREG).

\subsection{Publicidad de la contabilidad}

Como se señaló al principio de este apartado, un objetivo fundamental del control tiene que estar ligado al conocimiento general sobre las finanzas de los partidos, 
puesto que el origen de sus recursos y el destino de sus gastos deberían ser de dominio público, como el desarrollo de su actividad, en relación en ambos casos con el cumplimiento de sus importantes funciones en el sistema democrático: al hilo de la libertad con la que determinan sus elecciones, habría que conocer quién condiciona las decisiones que adoptan, además de que pueda contribuir a desincentivar prácticas corruptas (Martínez Cousinou, 2013: 68, citado por Sánchez Muñoz, 2013: 182).

A este fin apenas había contribuido la publicación de los informes del Tribunal de Cuentas, conforme al régimen general del funcionamiento de este órgano (así lo recoge el art. 16.5 in fine LOFPP): junto con la resolución de la Comisión mixta, se publican en el Boletín Oficial del Estado (previamente han sido objeto de publicación en el Boletín Oficial de las Cortes Generales, en tanto tienen que conocerlo los integrantes de la Comisión mixta). Facilita en todo caso esta tarea la existencia de versiones electrónicas abiertas de ambas publicaciones oficiales, así como que el propio Tribunal, en su página electrónica, también permita el acceso a sus informes.

Se trata en todo caso de textos de notable extensión (los referidos a la contabilidad anual ocupan varios centenares de páginas), con un elevado contenido técnico, lo que no contribuye precisamente al correcto conocimiento de esos datos, que deberían haber propiciado las propias formaciones políticas: así se ha entendido a partir de la reforma de la LOFPP de $2012^{37}$, que les obliga a publicar en su página electrónica el balance, la cuenta de resultados y en particular la cuantía de los créditos pendientes de amortización (con especificación de la entidad concedente, el importe otorgado, el tipo de interés y el plazo de amortización), las subvenciones recibidas $y$, en lo que constituye una de las novedades más importantes de la Ley orgánica 3/2015, también las donaciones y legados de importe superior a $25.000 €$ con referencia concreta a la identidad del donante o legatario (art. 14.8).

Atendiendo a algunas de las indicaciones recogidas en el informe GRECO 2013, que señalaba que no estaban claros ni los plazos en que debería tener lugar esa publicación ni las sanciones a imponer en caso de incumplir esta obligación, se ha introducido también en 2015 el plazo máximo que tienen, que es de un mes desde la fecha de envío al Tribunal de Cuentas: en todo caso, pues, van a transcurrir varios meses desde la conclusión del ejercicio anual. Dado que son datos que los partidos tienen que poner en conocimiento del Tribunal cada tres meses, podría encomendarse esta tarea, como propone Sánchez Muñoz (2015: 67), al propio Tribunal de Cuentas, que las podría difundir con esa misma periodicidad. En cuanto a las consecuencias que genera su incumplimiento, se ha previsto que se les retengan las subvenciones, como ya se indicó al tratar de éstas (equiparándolas por tanto a las que no están al corriente de sus obligaciones tributarias y con la Seguridad Social: art. 3.8).

\footnotetext{
${ }^{37}$ Poco después se aprobó la Ley de transparencia, que incluye a los partidos políticos como sujetos a los que se aplican sus disposiciones, pero sólo las relativas a la "publicidad activa" (art. 3), que están determinadas en forma muy genérica y parecen concebidas más bien para las Administraciones públicas, sin que les afecte en cambio lo dispuesto sobre derecho de acceso a la información pública. La falta de concreción acerca de las obligaciones de los partidos no ha sido cubierta por las normas de desarrollo y en las que integran el Derecho de partidos sólo es posible encontrar una mención en la LOFPP, ya reseñada, a este régimen de transparencia (que afecta a las Administraciones que otorgan subvenciones y no a los propios partidos). En todo caso, es indudable la conexión entre las previsiones que se recogen a continuación y los objetivos que se tratan de alcanzar con esas normas sobre transparencia, cuya orientación general debería guiar la práctica de los partidos, más allá de lo que establezcan las normas, corrigiendo así actitudes en absoluto respetuosas de estos principios.
} 
Aunque también se ha ampliado el contenido de esa información (hasta 2015, como ya se indicó, los datos sobre los donantes sólo los conocía el Tribunal de Cuentas), debe hacerse preservando el carácter de "datos especialmente protegidos" que tienen los incluidos en la relación anual de donaciones (disposición adicional segunda de la Ley orgánica 3/2015, no integrada en la LOFPP). Queda por tanto esta materia sujeta al régimen establecido en la Ley orgánica de protección de datos, por lo que, además de no afectar esta publicidad a todas las donaciones (recuérdese que el límite ha quedado fijado en $50.000 €$ ), de esa calificación parece derivarse la obligación de solicitar al donante su consentimiento para que sus datos sean difundidos, que debería prestarse en el momento de efectuar el ingreso (de modo que en caso de negarse la donación no podría realizarse). Ésta parece ser la solución legal al posible conflicto entre esta publicidad y otros bienes, entre los que en ocasiones se ha incluido la libertad ideológica y el consiguiente derecho a no declarar sobre creencias: con Sánchez Muñoz (2013: 193), se podría considerar que es un acto expresivo que no permite acogerse a ese derecho ${ }^{38}$.

En otro orden de cosas, sobre su posible carácter disuasorio, no parece que pueda tener mucha relevancia a la vista de los magros ingresos que reciben los partidos por esta vía. Citando el caso británico, Rodríguez Teruel, Baras, Barberà y Barrio (2013: 96) advierten que la publicidad puede resultar disuasoria, pero para que los partidos acepten donaciones de gran cuantía, ya que les haría aparecer como excesivamente vinculados a los intereses del donante. Convendría en todo caso que al tiempo que se solicita al donante el consentimiento para el tratamiento de sus datos se le informara también de las ventajas fiscales que le puede reportar, circunstancias que no estaría de más haber incluido en la ley.

En fin, sólo las donaciones de más de $25.000 €$ van a ser objeto de esta publicidad, lo que de entrada supone que únicamente se conocerá un número más bien limitado de donantes, ya que es un importe bastante elevado: de hecho, Ariño (2009: 32), que se muestra partidario cuando menos de equilibrar la importancia entre financiación pública y privada, dando mayor importancia a esta última, sostiene que deberían hacerse públicas las donaciones a partir de cantidades muy inferiores, 100 ó $150 €$ incluso, criterio que sería bastante más razonable que el actualmente vigente.

Además de esta información, a publicarse en los primeros meses del año siguiente de cada ejercicio, una vez emitido por el Tribunal de Cuentas el informe de fiscalización anual deberán también hacerlo público igualmente a través de su página electrónica en un plazo máximo de 15 días (art. 14.9). Similar obligación se ha introducido para las fundaciones: una vez emitido por el Tribunal de Cuentas el informe de fiscalización tienen que hacer públicos, preferentemente a través de su página electrónica, el balance y la cuenta de resultados así como las conclusiones del informe de auditoría, de forma que esta información sea de gratuito y fácil acceso para los ciudadanos (disposición adicional séptima).

A pesar de todos estos avances, que no son insignificantes, no se ha alcanzado el objetivo deseable en esta materia, que sería el de contar, como señala Sánchez Muñoz (2015: 51 y 65-66) con "una información completa, de fácil acceso, comprensible y disponible en tiempo útil": no está integrada por todos los elementos que debería incluir, no utiliza un lenguaje accesible para todos, sin especiales conocimientos técnicos ni se proporciona en un régimen de inmediatez, que permita

\footnotetext{
${ }^{38}$ En el informe GRECO 2009 se recogía la preocupación de las autoridades españolas acerca de los problemas de seguridad que podría crear para algunas personas objeto de la acción de bandas terroristas.
} 
formar la voluntad popular conforme se produzcan los hechos, aunque es cierto que a través de internet es posible encontrarla sin mayores dificultades.

\subsection{Sanciones}

Excluyendo la privación del cargo para los casos de irregularidades en las cuentas de campaña (básicamente porque no son individuales sino de las formaciones políticas, en sistemas de representación proporcional con distritos plurinominales, lo que impide su puesta en práctica, ya que afectaría sólo a una parte de los elegidos en la circunscripción, sin que resulte operativa la repetición de las elecciones que suele generar su aplicación en sistemas que utilizan un sistema de distritos uninominales cuando el candidato electo ha vulnerado las reglas sobre financiación), el ordenamiento español prevé por un lado algunos tipos penales directamente relacionados con las infracciones de estas normas y por otro sanciones de carácter económico, en forma de multas o sobre las subvenciones, que pueden ser reducidas o incluso denegadas a las formaciones políticas, en una materia en la que se han producido numerosas reformas desde la aprobación de la LOREG y la Ley orgánica 3/1987, a la vista de la deficiente regulación que contenía sobre todo esta última.

Comenzando por las más graves, hasta la reforma del Código Penal (CP) operada por Ley orgánica $1 / 2015$, de 30 de marzo (coincidiendo por tanto con la última reforma de la LOFPP), por la que se introduce un nuevo título, el XIII bis, dedicado a los "delitos de financiación ilegal de los partidos políticos", sólo podían ser sancionadas por la vía penal infracciones cometidas en periodo electoral, en la medida en que la LOREG, en la que se recogen específicamente los delitos electorales, sí incluye desde su redacción inicial algunos relacionados con esta materia (art. 140, 149 y 150). En definitiva, es necesario considerar una vez más este doble ámbito, con regulaciones no siempre coincidentes, de modo que en la actualidad están tipificados los siguientes delitos:

a) Donaciones ilegales (anónimas, por importe superior a $50.000 € \mathrm{o}$ procedentes de personas jurídicas), castigados con pena de multa del triplo al quíntuplo de su valor; la misma multa y también la pena de prisión de 6 meses a 4 años habrá que imponer si son de importe superior a $500.000 €$ o superan en esta cifra el límite y si proceden de extranjeros y superan el importe de $100.000 €$. Las mismas penas se impondrán a quien entregue esas donaciones (art. 304 bis CP).

b) Participación en estructuras u organizaciones, cualquiera que sea su naturaleza, cuya finalidad sea la financiación de partidos políticos al margen de lo establecido en la ley, castigada con la pena de prisión de 1 a 5 años (art. 304 ter $\mathrm{CP})^{39}$.

c) Como delitos de los que pueden resultar responsables los administradores electorales de cada formación política, los de falsedad de cuentas (reflejar u omitir indebidamente en las cuentas aportaciones o gastos o usando de cualquier artificio que suponga aumento o disminución de las partidas contables, castigado con pena de prisión de 1 a 4 años y multa de 12 a 24 meses: art. 149 LOREG) y apropiación indebida (apropiarse o distraer fondos para fines distintos de los previstos en la ley, castigado con pena de prisión de 1 a 4 años y multa de 6 a 12 meses, si los fondos apropiados o distraídos no superan los $50.000 €$ y de prisión de 2 a 6 años y multa de 12 a 24 meses, en caso contrario: art. 150 LOREG).

\footnotetext{
${ }^{39}$ Con expresa mención a la aplicación de las reglas sobre responsabilidad penal de las personas jurídicas, corresponderán las mismas penas a los partidos que sean responsables de los hechos, que pueden llegar incluso a la disolución del partido [en general, sobre este asunto la reciente STS (Penal) 154/2016, de 29 de febrero].
} 
d) Como delito que pueden cometer los funcionarios, incumplir, abusando de su oficio o cargo, las obligaciones relativas a certificaciones en materia de subvenciones por gastos electorales, castigado con las penas de prisión de 3 a 7 años y multa de 18 a 24 meses (art. 140 LOREG).

Al margen de la aplicación de estos tipos penales, la sanción de las restantes infracciones está ligada a la fiscalización del Tribunal de Cuentas ${ }^{40}$, en una gradación que, conforme a los art. 17 y 17 bis LOFPP, prevé:

a) Infracciones muy graves: donaciones ilícitas (que no sean delictivas), incluyendo la asunción por terceras personas de los gastos del partido y los acuerdos ilícitos sobre condiciones de deuda y el incumplimiento durante dos ejercicios consecutivos o tres alternos de la obligación de presentar las cuentas anuales o la presentación de cuentas incompletas o deficientes que impidan al Tribunal de Cuentas llevar a cabo su cometido fiscalizador; en el ámbito electoral también tendrá esta consideración superar el límite de gastos legalmente previsto en un $10 \%$ o más. Serán sancionadas con multa de doble al quíntuplo de la cantidad recibida indebidamente o del exceso en el que se haya incurrido y la falta de presentación con multa de entre 50.000 y $100.000 €$, con una importante novedad respecto al incumplimiento de esta obligación: la misma Ley orgánica 3/2015 modificó la LOPP para introducir por primera vez en el ordenamiento español un sistema de depuración del Registro de Partidos Políticos, mediante declaración judicial de extinción, entre otros motivos, por no haber presentado cuentas durante tres años consecutivos o cuatro alternos, decisión que corresponde adoptar a la jurisdicción contencioso-administrativa, previo apercibimiento del Registro para que en seis meses los partidos afectados puedan justificar la presentación (art. 12 bis LOPP). En el ámbito electoral, todos los excesos de gastos (con independencia de su calificación) también pueden generar que el Tribunal de Cuentas proponga la no adjudicación o la reducción de la subvención, conforme al art. 134.2 LOREG (en la práctica, sólo se aplica la denegación en caso de que no se entregue contabilidad, mientras que la reducción procedía en caso de rebasar los límites, en una cantidad equivalente al exceso en que se haya incurrido, previsión ahora derogada por la Ley orgánica 3/2015).

b) Infracciones graves: realización de actividades de carácter mercantil, incumplimiento de las obligaciones contables (incluidas la falta de presentación de las cuentas anuales o la presentación incompleta o con deficiencias que impidan al Tribunal de Cuentas llevar a cabo su cometido fiscalizador en supuestos no calificados como muy graves), la falta de un sistema de auditoría o control interno y la superación en más de un 3 y en menos de un $10 \%$ de los límites de gastos electorales. Las sanciones que corresponden a estas infracciones son de multa de entre 25.000 y $50.000 €$ más el beneficio neto obtenido por la realización de las actividades mercantiles, del doble al quíntuplo del exceso del gasto producido sin que en ningún caso pueda ser inferior a 25.000 euros y de un mínimo de $10.000 €$ y un máximo de $50.000 €$ para las restantes.

c) Infracciones leves: faltas al deber de colaboración (sancionadas con multa de entre 5.000 y $10.000 €$ ) y superación por los partidos políticos en más de un 1 y hasta un $3 \%$ de los límites de gastos electorales (sanción del doble al quíntuplo del exceso, sin que en ningún caso pueda ser inferior a $5.000 €$ ).

\footnotetext{
${ }^{40}$ En realidad, en el ámbito electoral se prevé que las infracciones no delictivas pueden dar lugar a la imposición por la Administración electoral de una multa de 300 a $3.000 €$ si son responsables autoridades o funcionarios y de 100 a $1.000 €$ si se realiza por particulares (art. 153 LOREG).
} 
Este sistema resulta mucho más completo que las previsiones anteriores, criticado en el informe GRECO 2011, que inicialmente sólo operaban sobre las subvenciones: no se adjudicaban si no se presentaban cuentas y se reducían si había infracciones, lo que hacía que el control tuviera un carácter hasta cierto punto voluntario, pues los partidos no tenían más incentivo para someterse a él que el de disfrutar de la subvención. Abría la posibilidad, por tanto, de que las formaciones que tuviera recursos suficientes, incluso obtenidos de forma abiertamente irregular, se mantuvieran al margen de ese control; en el ámbito electoral, más concretamente, muchas candidaturas que concurren a elecciones municipales en un número muy reducido de circunscripciones, incluso sólo en una, porque no cuentan con la organización precisa o les resulta excesivamente costoso o complicado, no cumplen con esta obligación, sin que verse privadas de una subvención muy reducida, a la vista del escaso número de votos y concejales obtenidos, les vaya a suponer mayores problemas económicos ${ }^{41}$. Ahora ya no es posible eludir la fiscalización del Tribunal de Cuentas, a la vista de las sanciones que se imponen, que pueden llevar incluso a la extinción del partido (que seguramente se va a aplicar más en casos de inactividad de tantas formaciones inscritas en el Registro que para incumplimientos reiterados con carácter deliberado, que por lo demás tampoco se habían producido, ni va a afectar tampoco a esas formaciones de ámbito municipal en tanto la mayoría concurren a las elecciones como agrupaciones de electores).

La posterior introducción de multas, en buena medida por la reiterada reclamación del Tribunal de Cuentas, en razón de la cantidad indebidamente recibida $o$ en la que se produjo el exceso, que ahora se mantiene, pero incrementando el volumen de las sanciones, probablemente obedezca a que no han sido lo suficientemente disuasorias (tampoco se puede saber a ciencia cierta, ya que se introdujeron en 2012, por lo que no ha habido ocasión de constatar su aplicación: recuérdese que el último informe anual que se conoce es del ejercicio siguiente) $)^{42}$. Por último, se recogen ahora como infracciones actos que no estaban sancionados en las normas anteriores (acuerdos sobre deuda, cumplimiento de requisitos formales, realización de actividades mercantiles).

Mención aparte merece el tratamiento penal, que por un lado pone fin a esa situación conforme a la cual estaban previstas estas sanciones en el ámbito electoral pero no en el de la financiación ordinaria, lo que no tenía mayor justificación, si bien es fácilmente observable que el CP y la LOREG recogen tipos entre los que no se pueden establecer muchos paralelismos (donaciones y financiación ilícita en aquel, falsedad y apropiación en ésta). Al menos, queda clara la relevancia penal de ciertos actos que hasta ahora sólo eran perseguibles por esta jurisdicción acudiendo a tipos no específicamente referidos a la financiación partidista (falsedades, malversaciones, delitos contra la Hacienda pública...), si bien la descripción de algunos tipos no resulte lo suficientemente precisa: como sostiene Olaizola (2015: 2-4), deben reservarse para conductas que supongan una perturbación de la manifestación de la voluntad popular, no para perseguir cualquier irregularidad; no se ha tenido en cuenta si en la infracción está involucrada la Administración, para atender en cambio en exclusiva a la cantidad, cuando lo que se protege no es el orden socioeconómico, sino las funciones constitucionales de manifestación de la voluntad popular que cumplen los partidos.

\footnotetext{
${ }^{41} \mathrm{El}$ dato que recoge Iglesias (2016: 142) es suficientemente expresivo: de acuerdo con el informe del Tribunal de Cuentas sobre las elecciones municipales de 22 de mayo de 2011 tenían que haber presentado contabilidad electoral 1.680 formaciones políticas, pero no lo hicieron más de mitad, 881 .

${ }^{42}$ La situación anterior era tan confusa que lleva a Maroto, Anderica, Baleato y Ongil (2013: 31) a preguntarse si las sanciones propuestas llegaron efectivamente a cumplirse.
} 
Finalmente, la LOFPP ha establecido un procedimiento sancionador que es de aplicación en cualquiera de los dos ámbitos en los que se desarrolla esa fiscalización, con lo que por lo demás se despejan todas las dudas que había hasta 2007 acerca del órgano al que correspondía ejercer la potestad sancionadora: según su art. 18, tras la apertura de un periodo de información previa, con audiencia al partido que haya podido cometer la infracción, se inicia con un acuerdo del pleno del Tribunal de Cuentas en el que conste la formación infractora, los hechos que integran la infracción (calificación y posible sanción) y la designación de instructor. Hay un plazo para presentar alegaciones (15 días) y solicitar la práctica de pruebas (también la puede acordar el instructor de oficio; de acordarse, se practicarán en un plazo de 30 días); tras la propuesta de resolución, hay 15 días para presentar alegaciones. La resolución del pleno tiene que recaer antes de que transcurran seis meses desde la iniciación del procedimiento, que caduca si no se resuelve en ese plazo, salvo que la demora la hayan causado los interesados. Cabe recurso ante la sala de lo contencioso-administrativo del Tribunal Supremo, con un carácter suspensivo si tienen carácter sancionador. La apertura del procedimiento no impide ejercer la función fiscalizadora e imponer las multas previstas en la LFTCu ni tampoco interrumpe el cómputo de la prescripción.

También se ha diversificado el plazo de prescripción de estas infracciones, que se estableció en 2012 con carácter general en cuatro años, mientras que ahora es de cinco para las muy graves, tres para las graves y dos para las leves, iniciándose el cómputo de estos plazos en el momento de la comisión de la infracción (art. 17.5 LOFPP) ${ }^{43}$. Hay que recordar en todo caso, sobre todo a la vista del retraso con el que el Tribunal elabora sus informes (aunque reducido en los últimos ejercicios), que para abrir el procedimiento sancionador no es necesario haber concluido el informe de fiscalización, que tiene otro objeto y otro destinatario: no hay que esperar a la aprobación del informe ni mucho menos a la resolución de la Comisión mixta para que el Tribunal de Cuentas ejerza esa potestad sancionadora, que hay que recordar sólo se le otorgó expresamente con la aprobación de la Ley orgánica 8/2007, que reguló asimismo el procedimiento que había de seguir (la Ley orgánica 3/1987 contenía sanciones, pero no especificaba cuál el órgano que debía administrarlas $)^{44}$.

En todo caso, la imposición de las sanciones sigue teniendo repercusión sobre las subvenciones, ya que el Tribunal de Cuentas tiene que vigilar que aquéllas se hagan efectivas antes del libramiento de la siguiente subvención y que se detraiga su importe en el caso de no haber sido satisfechas; en aquellos casos en que el partido político sancionado no tenga derecho a la percepción de subvenciones, debe requerirle para que proceda al ingreso del importe correspondiente a la sanción en el Tesoro Público. Y para el caso de haber hecho efectivo el pago de la sanción impuesta, debe dar traslado a la Agencia Estatal de la Administración Tributaria para que ésta proceda a su recaudación en periodo ejecutivo (art. 17 bis.4).

El papel central que le corresponde al Tribunal de Cuentas en estas tareas de control y la generalizada insatisfacción que ha generado ha dado lugar a críticas no siempre justificadas: algunas se han centrado en la forma de designación de sus miembros, en la medida en que son los partidos (mayoritarios) los que deciden quienes van a formar parte del órgano encargado de fiscalizar sus cuentas, de lo que se derivaría un trato no muy exigente, incluso al contrario, más bien favorable,

\footnotetext{
43 Coinciden Sánchez Muñoz (2015: 69) e Iglesias (2016: 148) en que el de cuatro años era insuficiente, por lo que había que ampliarlo a fin de evitar que quedaran impunes algunas infracciones.

${ }^{44}$ En contra del criterio expresado en el texto sobre la posibilidad de abrir el procedimiento sancionador antes de concluir el informe, Iglesias (2016: 128).
} 
como para Maroto, Anderica, Baleato y Ongil (2013: 31), que llegan a calificar de "parapeto" su actuación por ejemplo en el caso Filesa. Sin despreciar estas circunstancias que encajan con la llamada colonización por los partidos de esos órganos de control cuya composición depende en todo o en parte de instancias políticas (los controlados en suma deciden sobre los controladores, aunque no tiene un alcance unívoco para todos ellos ${ }^{45}$ ) y aún menos las que se refieren a algunas decisiones concretas sobre el acceso a esa condición de consejero del Tribunal de Cuentas de quienes no contaban con mayores cualificaciones técnicas o habían ocupado en el pasado (a veces no muy remoto) carteras ministeriales o escaños en el parlamento, que de entrada no propician una situación muy adecuada, a las que se podrían añadir otras sobre medios técnicos y personales (que es muy probable que no sean los suficientes) o a la sobrecarga de trabajo de un órgano que tiene que fiscalizar cuentas del Estado, de comunidades autónomas, de municipios, de empresas y entidades públicas..., pueden encontrarse en la misma configuración de la fiscalización de la contabilidad de los partidos otras deficiencias que explican también e incluso en mayor medida las insuficiencias de ese control.

Por un lado, hay que tener en cuenta que el Tribunal de Cuentas elabora sus informes a partir de la documentación que le proporcionan los propios partidos, por lo que no puede llevar a cabo, como dice Sánchez Muñoz (2013: 174) "una auténtica labor investigadora"; incluso a pesar de haber transcurrido ya más de 30 años desde que esta fiscalización empezara a practicarse, el Tribunal de Cuentas sigue advirtiendo en ocasiones de que los datos no son completos, no se atienen a la práctica contable o no se aporta la documentación apropiada, defectos que no son tan graves como para haber acarreado la imposición de la sanción correspondiente pero que reflejan la confusión en la que desarrollan sus actividades los partidos.

Las recientes modificaciones legales han ampliado en cierta medida la capacidad de recabar información de otras entidades, pero no cabe esperar de esos cambios ni en realidad de otros que en el futuro pudieran incluso aumentar esa facultad una respuesta enteramente satisfactoria sobre su capacidad para penetrar en la realidad económica de los partidos, salvo que pasara de ser un órgano de control externo a tener otra naturaleza... Quizá entonces fuera mejor encomendar esas tareas a otro órgano, de nueva creación, encargado exclusivamente del control económico de los partidos, con más amplias facultades, prácticamente equiparables a los jurisdiccionales, si bien la existencia de este tipo de órganos tampoco garantiza en sí misma que no haya infracciones ni que se detecten y se sancionen todas las que hay, con rigor y prontitud, aunque quizá sí mayor y más pronta publicidad, sanciones más operativas... ${ }^{46}$.

No hay que olvidar tampoco que, en tanto fiscaliza las cuentas y la gestión económica del Estado, así como del sector público, su control resulta adecuado cuando se centra en los gastos, aspecto sobre cuya legalidad y regularidad puede pronunciarse a partir de la información de que dispone (como ya se ha destacado respecto a los gastos electorales y de seguridad), mientras que resulta mucho más alejada de esa tarea de control contable del sector público la comprobación de esas mismas condiciones respecto a los ingresos, sobre todo de particulares, lo que sin

\footnotetext{
${ }^{45}$ Cabe recordar que el Tribunal de Cuentas depende directamente de las Cortes Generales y ejerce algunas de sus funciones por delegación de ellas.

${ }_{46}$ Un modelo a seguir podría ser, en ese caso, la Comisión nacional de cuentas de campaña y de financiación política creada en Francia en 1990, con la condición de autoridad administrativa independiente, integrada por tres miembros del Consejo de Estado (que tiene atribuidas funciones de justicia administrativa), tres de la Corte de Casación y otros tres de la Corte de Cuentas, con amplias funciones de control y sanción.
} 
duda ha propiciado la descalificación más o menos generalizada que ha merecido el Tribunal de Cuentas.

Bibliografía

ARIÑO, G. (2009), La financiación de partidos y candidatos en las democracias occidentales, Foro de la Sociedad Civil, Madrid.

DEL CASTILLO, P. (1985), La financiación de partidos y candidatos en las democracias occidentales, Centro de Investigaciones Sociológicas, Madrid.

DOUBLET, Y-M. (1991), Le financement des partis politiques en République Fédérale d'Allemagne, Economica, Paris.

DOUBLET, Y-M. (1993), "L'arrêt de la Cour constitutionnelle fédérale allemande du 9 avril 1992 sur le financement des partis politiques", Revue française de droit constitutionnel, 15, pp. 663-668.

GÁLVEZ, L. (2010), Las campañas institucionales: normas, doctrina de la Junta Electoral Central y jurisprudencia, Thomson Reuters-Aranzadi, Cizur Menor.

GAVARA, J.C. (2009), "La financiación electoral en el ámbito autonómico". En: GÁLVEZ, L. (coord.), El derecho electoral de las Comunidades Autónomas: revisión y mejora, Madrid, Centro de Estudios Políticos y Constitucionales, pp. 257-312.

GONZÁLEZ, S. y MAROTO, M. (2015), "La financiación participativa en partidos como herramienta de cambio político". eldiario.es [online], 10 de mayo de 2015. Disponible en: http://www.eldiario.es/ 16f84d64 (fecha de consulta: 28 de enero de 2016).

IGLESIAS, M. (2016), "Dinero y Votos. Un balance crítico de la financiación electoral de los partidos en España". En: CASCAJO, J.L. y MARTÍN DE LA VEGA, A. (coord.), Participación, representación y democracia, Valencia, Tirant Lo Blanch, pp. 123-149.

LÓPEZ DE LA FUENTE, G. (2014), Pluralismo político y partidos políticos europeos, Comares, Granada.

LUCAS MURILLO DE LA CUEVA, P. (1993), "La financiación de los partidos y de las elecciones. La legislación interminable", Revista Vasca de Administración Pública, núm. 37, pp. 107-131.

MAROTO, M., ANDERICA, A., BALEATO, S. y ONGIL., M (2013), Qué hacemos con la financiación de los partidos, Akal, Madrid.

MARTÍNEZ COUSINOU, G. (2013), El control de la corrupción política en el ámbito de la financiación de los partidos: actores, intereses y estrategias en España y Reino Unido, tesis doctoral presentada en la UNED.

OLAIZOLA, I. (2015), "El delito de financiación ilegal de partidos políticos en la reforma del CP", Diario La Ley, 2637, pp. 1-8.

PAJARES, E. (1998), La financiación de las elecciones, Congreso de los Diputados, Madrid.

PAJARES, E. (2004), "La financiación y la campaña electoral en los regímenes electorales autonómicos", Cuadernos de Derecho Público, núm. 22-23, pp. 239-268.

PAJARES, E. (2008), "Algunas notas sobre la regulación constitucional y legal del referéndum a la luz de su (escasa) experiencia”. En: CARRILLO, M. (coord.), Estudios sobre la Constitución Española. Homenaje al profesor Jordi Solé Tura, Madrid, Cortes Generales/Centro de Estudios Políticos y Constitucionales/Universitat de Barcelona/Ajuntament de Mollet del Vallès, pp. $759-776$.

RIDAO, J. (2014), "La transparencia y el control económico-financiero de los partidos políticos en España. Entre un balance decepcionante y un futuro sombrío", Cuadernos Manuel Giménez Abad, núm. 7, pp. 211-222. 
RODRÍGUEZ LÓPEZ, Á. y FIDALGO, E. (2012), "Responsabilidad social, crisis financiera y normalización contable en los partidos políticos españoles", CIRIEC-España, Revista de Economía Pública, Social y Cooperativa, núm. 74, pp. 239-259.

RODRÍGUEZ TERUEL, J., BARAS, M., BARBERÀ, Ó. y BARRIO, A. (2013), Financiación de los partidos y transparencia democrática. Buenas prácticas en Europa y América del Norte, Fundació Catalunya Europa, Barcelona.

SÁNCHEZ MUÑOZ, Ó. (2013), "La financiación de los partidos políticos en España: ideas para un debate", Revista Española de Derecho Constitucional, núm. 99, pp. 161-200.

SÁNCHEZ MUÑOZ, Ó. (2015), "La insuficiente reforma de la financiación de los partidos: la necesidad de un cambio de modelo", Revista Española de Derecho Constitucional, núm. 104, pp. 49-82.

VALERO, A. (2012), "Citizens United y la financiación de las campañas electorales en el Derecho norteamericano", Teoría y Realidad Constitucional, núm. 30, pp. 433-453. 